\title{
Adsorptive Removal of Cd(II) Ions from Wastewater Using Maleic Anhydride Nanocellulose
}

\author{
Hizkeal Tsade Kara $\mathbb{D}^{1},{ }^{1}$ Sisay Tadesse Anshebo $\mathbb{D}^{2},{ }^{2}$ and Fedlu Kedir Sabir $\mathbb{D D}^{1}$ \\ ${ }^{1}$ Department of Applied Chemistry, School of Applied Natural Science, Adama Science and Technology University, P.O.Box 1888, \\ Adama, Ethiopia \\ ${ }^{2}$ Department of Chemistry, College of Natural and Computational Science, Hawassa University, P.O. Box 05, Hawassa, Ethiopia
}

Correspondence should be addressed to Hizkeal Tsade Kara; hizts4@gmail.com

Received 18 March 2021; Revised 5 June 2021; Accepted 10 June 2021; Published 18 June 2021

Academic Editor: Eduard Llobet

Copyright (C) 2021 Hizkeal Tsade Kara et al. This is an open access article distributed under the Creative Commons Attribution License, which permits unrestricted use, distribution, and reproduction in any medium, provided the original work is properly cited.

\begin{abstract}
In this study, both pristine cellulose nanocrystalline (CNC) and maleic anhydride functionalized cellulose nanocrystalline (MACNC) were prepared from the stems of Eichhornia crassipes weed by the sulfuric acid hydrolysis method. The as-prepared adsorbents were characterized by using X-ray diffraction (XRD), Fourier-transform infrared (FTIR) spectroscopy, scanning electron microscopy (SEM), energy-dispersive X-ray (EDX), and Brunauer-Emmett-Teller (BET) instruments. These materials were applied for the removal of Cd(II) ions from WW. The uptake mechanism was fixed to both Langmuir and Freundlich adsorption isotherms with a maximum Cd(II) ion uptake capability $\left(q_{\max }\right)$ of 75.76 and $215.52 \mathrm{mg} \mathrm{g}^{-1}$ by CNC and MA-CNC adsorbents, respectively. Pseudo-second-order (PSO) kinetic model was well fitted to the uptake process. The adsorbent regeneration study was done after desorption of $\mathrm{Cd}(\mathrm{II})$ ions from the adsorbent by $\mathrm{HCl}$ washing. Results exhibited that the adsorbent was reused for the removal of Cd(II) ions from real WW after successive $13^{\text {th }}$ cycle.
\end{abstract}

\section{Introduction}

Currently, the pollution of the environment by different toxic pollutants, such as heavy metals, dyes, and pesticides, has stimulated great concern and is the most focusing issue in developing countries [1]. The sources for these pollutants are different natural and anthropogenic activities, such as domestic, industrial, and agricultural activities. These pollutants enter into the water bodies through the release of different pollutant-containing effluents. Among these, the pollution of the environment by heavy metals causes severe environmental effects because, unlike organic pollutants, heavy metals are nonbiodegradable. These heavy metals are arsenic (As), lead $(\mathrm{Pb})$, chromium $(\mathrm{Cr})$, copper $(\mathrm{Cu})$, zinc $(\mathrm{Zn})$, cobalt $(\mathrm{Co})$, molybdenum $(\mathrm{Mo})$, and manganese $(\mathrm{Mn})$ [2]. Cd is one representative example of toxic metals entering the environment from industrial effluent and poses a potential risk to the whole environment in general and wastewater in particular because of its nonbiodegradable nature, carcinogenicity, persistence, and bioaccumulation. The presence of Cd can harmfully affect the achievement of the wastewater treatment processes and lead to serious risks to the environment [3]. Subsequently, the efficient removal of Cd(II) ions from real wastewater before its discharge into the environment was one of the best options for the quality of water.

In the $21^{\text {st }}$ century, a lot of technologies were tested to remediate augmented poisonous waste discharges from the wastewater [4]. These are chemical precipitation, chemically enhanced primary treatment (CEPT), filtration, reverse osmosis, solvent extraction, ion exchange, coagulation, and adsorption [5, 6]. Most of these technologies need high prices, have relatively low remediation capabilities, and call for further treatments [7]. For instance, chemically enhanced primary treatment (CEPT) methods can remove the $\mathrm{Cd}(\mathrm{II})$ ions levels partially, but the complete removal of $\mathrm{Cd}(\mathrm{II})$ ions is not guaranteed. Furthermore, this technique leads to the production of an increased number of alkaline 
sludge. The other abovementioned techniques have similar drawbacks, and more efficient treatment ways are required currently. Therefore, among these techniques, adsorption seems to be the most one owing to its simple operation, costfriendly, very high remediation sensitivity, augmented uptake capability, and easy availability as adsorbent materials like activated carbon, carbon nanotubes (CNT), composites, and nanoparticles [8-13].

Recently, most thematic adsorption studies focused on low-cost, renewable, and easily recyclable adsorbent materials, such as polymeric materials including cellulose, chitin, chitosan, gelatin, alginate, and starch for the eradication of noxious nutrients from aqueous media has been the $21^{\text {st }}$ century choices. Despite its increased properties, the limitations of cellulose-based materials in wastewater remediation processes have shown that the decreased hydrophilicity, low physical and chemical stability, and low pollutants uptake capability $[14,15]$. This drawback can be resolved by bringing cellulose into nanocellulose in order to enhance its pollutant uptake capabilities [16]. Thus, in this study, cellulose nanocrystallines (CNCs) were selected as a good adsorbent for $\mathrm{Cd}$ (II) ions remediation from wastewater due to their bioavailability, biocompatibility, sustainability, environmentally friendly, renewability, having high aspect ratio, having better physical and chemical stability, and abundant active and reactive surface $[17,18]$.

Several research studies were reported on CNC adsorbents with a high specific surface area ranging from $52 \mathrm{~m}^{2} \mathrm{~g}^{-1}$ to $107 \mathrm{~m}^{2} \mathrm{~g}^{-1}$, based on the preparation methods $[19,20]$. It is known that the high surface areas and small particle sizes are very significant for the efficient $\mathrm{Cd}(\mathrm{II})$ ions removal mechanisms. CNCs characteristically have low removal capability and less dimensional stability. One can improve these problems through the functionalization of CNCs by adding extra anions or cations into the surface of CNCs [21-25]. Chemical surface modification of CNCs has substantial removal capabilities toward different pollutants from contaminated effluents [26-28].

Previously, many research studies have been carried out on the CNMs based adsorbents synthesized from different biobased materials such as plant materials, date palm (Phoenix dactylifera L.) [29], Cotton residue [30], banana [31], corn husk [32], Erythrina brucei plant [33], and Millettia ferruginea plant [34]. To the best of the author's knowledge, insufficient research papers are reported on the CNCs sorbents synthesized from the stems of Eichhornia crassipes weed. This material was completely waste material that has not any negative economic impact on societies. This material has plenty of hydroxyl, carbonyl, and ester functional groups that are responsible for the efficient adsorption of Cd(II) ions from wastewater. This is due to the presence of hydrogen bonding between the positively charged $\mathrm{Cd}$ (II) ions and $\mathrm{OH}$ functional groups of CNCs adsorbents. Thus, using waste material instead of useful material as Cd(II) ions removing reagent from wastewater is cost-effective for developing countries. Furthermore, most of the research studies reported in the literature were on the removal of $\mathrm{Cd}(\mathrm{II})$ ions from synthetic wastewater only, but there is a dearth of information regarding the removal of $\mathrm{Cd}(\mathrm{II})$ ions from real wastewater. Therefore, the study focused on the preparation and characterization of pristine $\mathrm{CNC}$ and maleic anhydride-modified MA-CNC adsorbents from the stems of Eichhornia crassipes weed to remove Cd(II) ions from real wastewater.

\section{Materials and Methods}

2.1. Materials and Chemicals. The stems of Eichhornia crassipes weed, for CNCs preparation, were collected from Southern Region "Ganta Garo" Lake abaya, Gamo Zone, Ethiopia. The wastewater (WW) sample was collected from the run-off Modgo River, Oromia Region, Ethiopia. All the reagent grades are toluene (99\%, Loba Chemie Pvt. Ltd, India), ethanol (97\%, Tradewell International Pvt. Ltd, India), sodium hydroxide (99\%, Shraddha Associates (GUJ) Pvt. Ltd., India), conc. hydrochloric acid (35\%, Loba Chemie Pvt. Ltd., India), conc. sulfuric acid (69\%, Loba Chemie Pvt. Ltd., India), conc. nitric acid (69\%, Loba Chemie Pvt. Ltd., India), sodium chlorite ( $80 \%$, Shanghai ZZ New Material Tech. Co., Ltd., China), sodium bicarbonate (99\%, Shraddha Associates (GUJ) Pvt. Ltd., India), and cadmium nitrate (Cd $\left(\mathrm{NO}_{3}\right)_{2}$ (SDFCL, India)).

2.2. Experimental Procedures. The stock solution of $\mathrm{Cd}(\mathrm{II})$ ions was prepared by taking a $1000 \mathrm{~mL}$ volumetric flask and adding the required amount in a gram of $\mathrm{Cd}\left(\mathrm{NO}_{3}\right)_{2}$ into the flask. Then, to this flask certain volume of distilled water was added. The dilute solutions were prepared by adding a sufficient amount of distilled water to the previously prepared stock solution of the $\mathrm{Cd}(\mathrm{II})$ ions. The collected WW physicochemical property $(\mathrm{pH}, \mathrm{EC}, \mathrm{COD}, \mathrm{BOD}, \mathrm{TIN}, \mathrm{TP}$, $\mathrm{NO}_{3}^{-}, \mathrm{Ca}^{2+}$, and $\mathrm{Mg}^{2+}$ ) measurements were performed using different standard series. Next to this, it was spiked with $20 \mathrm{mg} \mathrm{L}^{-1}$ of Cd(II) ions solution and kept in suitable places for the experimental procedures.

\subsection{Preparation of Cellulose Nanomaterials from Eichhornia} crassipes. The stems of the collected Eichhornia crassipes weed sample were cut in the length of $8 \mathrm{~mm}$, washed with distilled water several times to remove any dust particles, dried with the sun for 4 days, and ground using a grinder carefully to form coarse particles [35-38]. The coarse particles were treated with $100 \mathrm{~mL}$ of $2.5 \mathrm{M} \mathrm{NaOH}$ solution at $50^{\circ} \mathrm{C}$ for 3 hours to remove the lignin and hemicelluloses present in lignocellulosic biomass. This mixture was washed well with deionized water repeatedly until the $\mathrm{pH}$ of 7 , and the washed liquid wastes were managed properly in the laboratory. Thereafter, the neutral mixture was filtered, centrifuged, and dried in the oven at $50^{\circ} \mathrm{C}$ for 10 hours. Then, it was ground into a pulp form and bleached with a ratio of $2: 1$ mixture volume of sodium chlorite $\left(\mathrm{NaClO}_{2}\right)$ and glacial acetic acid for 3 hours at $80^{\circ} \mathrm{C}$ under mechanical stirring. Then, it was centrifuged, washed, and filtered to form cellulose suspension. This procedure was repeated with half the initial amount of bleaching agents. Even though the sulfuric acid hydrolysis method produces a large number of liquid wastes to the environment compared to organic acids, it 
removes all hemicellulose from cellulosic components and it makes the nanocellulose dispersed as a stable colloid system due to the esterification of the hydroxyl group by sulfate ions [8]. Therefore, the mixture was hydrolyzed by $100 \mathrm{~mL}$ of $6 \mathrm{M}$ $\mathrm{H}_{2} \mathrm{SO}_{4}$ for 2 hours to break up the cell wall and to form a white nanocellulose suspension. During this process, a number of liquid wastes that are harmful to the working environments are produced. This problem was managed through a scientific and sensible liquid waste management system. Then, the produced white suspension was centrifuged at $16000 \mathrm{rpm}$ to separate the nanocellulose and homogenized in homogenizer at about $12,000 \mathrm{rpm}$ for 2.5 hours. The separated nanocellulose was washed repeatedly until the $\mathrm{pH}$ of 7 , filtered, and dried to form cellulose nanocrystalline (CNC). Finally, the prepared CNC was kept in a suitable place for characterization purposes. The flowchart representation of CNC preparation is given in Figure 1.

\subsubsection{Preparation of Chemically Modified (Maleic Anhy- dride) Cellulose Nanocrystalline (CNC): Esterification.} About $50 \%$ of the world's maleic anhydride yield is used in the manufacture of unsaturated polyester resins (UPR), and here, it was used as esterification processes by combining with CNC. CNC properties were improved by the esterification process with maleic anhydride by modification of the method reported in the literature [39]. Firstly, the obtained $\mathrm{CNC}$ was washed with the help of glacial acetic acid in order to make the chemical modification of $\mathrm{CNC}$ easy and to exchange the solvent. For this purpose, $15 \mathrm{~g}$ of previously prepared CNC was mixed with maleic anhydride by consecutively washing and centrifuging with glacial acetic acid four times for the purposes of solvent exchange. Then, this mixture was placed in a $500 \mathrm{~mL}$ beaker containing $170 \mathrm{~mL}$ of acetic acid and $210 \mathrm{~mL}$ of toluene and homogenized in a magnetic stirrer at $50^{\circ} \mathrm{C}$ for $2 \mathrm{hrs}$. Next to the homogenization procedure, $2 \mathrm{~mL}$ of $0.12 \mathrm{M}$ sulfuric acid was added, the sonication processes were carried out for $1 \mathrm{~min}$ with the help of ionic liquid, and then, $1.5 \mathrm{~g}$ of maleic acid anhydride was added. The reaction mixture was kept at room temperature for $90 \mathrm{~min}$. After the completion of this reaction, the maleic anhydride functionalized cellulose nanomaterial suspension was sequentially washed and centrifuged with toluene, methanol, and dichloromethane solvents. The purpose of solvent exchange during the preparation of MA-CNC is to remove nonpolar liquid wastes and polar liquid wastes using these nonpolar and polar solvents, respectively. Using toluene and dichloromethane solvents, the nonpolar wastes are removed, and using methanol and water solvents, the polar wastes are removed from the MA-CNC adsorbents. The sequentially washed maleic anhydride functionalized cellulose nanomaterial suspension was filtered and dried to form maleic anhydride functionalized cellulose nanocrystalline (MA-CNC). The esterification reaction of $\mathrm{CNC}$ with maleic anhydride (MA) is given in Figure 2.

2.4. Characterization. The crystallite size of both CNC and MA-CNC adsorbents was characterized by using XRD
(XRD-7000 X-ray diffractometer, Shimadzu Co., Japan) with $\mathrm{Cu}-\mathrm{K} \alpha$ radiation $(\lambda=0.154 \mathrm{~nm})$ at $40 \mathrm{kV}$ and $40 \mathrm{~mA}$ under a $2 \theta$ diffraction angle from $0^{\circ}$ to $80^{\circ}$ at a scan rate of $2^{\circ} / \mathrm{min}$. The functional group of the as-synthesized CNC and MA$\mathrm{CNC}$ sorbent materials were identified using the Fouriertransform infrared spectroscopy (FTIR) (Perkin Elmer65, PerkinElmer, Inc., Waltham, USA). The surface morphology of the different treatment phases of both CNC and MA-CNC adsorbents was examined using a Hitachi S-4100 scanning electron microscope (SEM). The specific surface area measurement was determined by the Brunauer-EmmettTeller (BET) analysis.

2.5. Adsorption Experiments. To determine the Cd(II) ion adsorption efficiency of CNC and MA-CNC adsorbents, batch experiments were conducted. In this experiment, each experimental parameter such as the initial concentration of $\mathrm{Cd}$ (II) ions ranged from 5 to $40 \mathrm{mg} / \mathrm{L}$, the adsorbent dosage ranged from 0.04 to $1.5 \mathrm{~g}$, the contact time ranged from 30 to $180 \mathrm{~min}$, solution $\mathrm{pH}$ ranged from 2 to 12 , and the temperature ranged from 20 to $45^{\circ} \mathrm{C}$ by making the rest parameters at fixed manner. Each of these parameters was accomplished in $100 \mathrm{~mL}$ flasks at the temperature of $20^{\circ} \mathrm{C}$ through shaking by an orbital shaker. Initially, the $\mathrm{pH}$ value of each solution was calibrated by the addition of $0.1 \mathrm{M} \mathrm{HCl}$ or $0.1 \mathrm{M} \mathrm{NaOH}$ solution, and the $\mathrm{pH}$ change was measured using a $\mathrm{PH}$ meter ( $\mathrm{pH} 21$ Hanna instrument). Then, each flask containing these solutions was covered with aluminum foil in all experiments to prevent any contaminant reactions with this solution, and after the reaction completion, it was carefully filtered with filtrate paper No. 42. After this, the measurement of this solution was done by an Atomic Absorption Spectrophotometer (Shimadzu, USA).

2.5.1. Adsorption Isotherms. Here, measuring the adsorption isotherms helps to quantify the affinity of the removal of $\mathrm{Cd}$ (II) ions from wastewater by $\mathrm{CNC}$ and $\mathrm{MA}-\mathrm{CNC}$ adsorbents. Mathematically, the affinity of the $\mathrm{Cd}(\mathrm{II})$ ion uptake for $\mathrm{CNC}$ and MA-CNC adsorbents was measured using adsorption isotherms. Thus, the adsorption of $\mathrm{Cd}(\mathrm{II})$ ions by using CNC and MA-CNC sorbents was done by using equations (1) and (2). From this equation, one can understand that the amount of $\mathrm{Cd}(\mathrm{II})$ ions adsorbed onto the CNC and MA-CNC adsorbents is equal to the amount of $\mathrm{Cd}(\mathrm{II})$ ions that were removed from the WW.

$$
\begin{gathered}
q_{e}=\frac{C_{i} \mathrm{Cd}(\mathrm{II})-C_{e} \mathrm{Cd}(\mathrm{II})}{S}, \\
q_{t}=\frac{C_{i} \mathrm{Cd}(\mathrm{II})-C_{t} \mathrm{Cd}(\mathrm{II})}{S},
\end{gathered}
$$

where $q_{e}$ and $q_{t}$ represent the amount of heavy metal adsorbed on the adsorbent surface at equilibrium and at any specific time $\left(\mathrm{mg} \mathrm{g}^{-1}\right)$, respectively. $C_{i}, \mathrm{Cd}(\mathrm{II})$ and $C_{e}, \mathrm{Cd}(\mathrm{II})$ represent the initial and equilibrium concentration of the heavy metal in the WW sample $\left(\mathrm{mg} \mathrm{L}^{-1}\right)$, respectively, and $C_{t}$ is the concentration of $\mathrm{Cd}(\mathrm{II})$ ions in wastewater samples $\left(\mathrm{mgL}^{-1}\right)$ at a specific time. $S$ represents the slurry dosage 


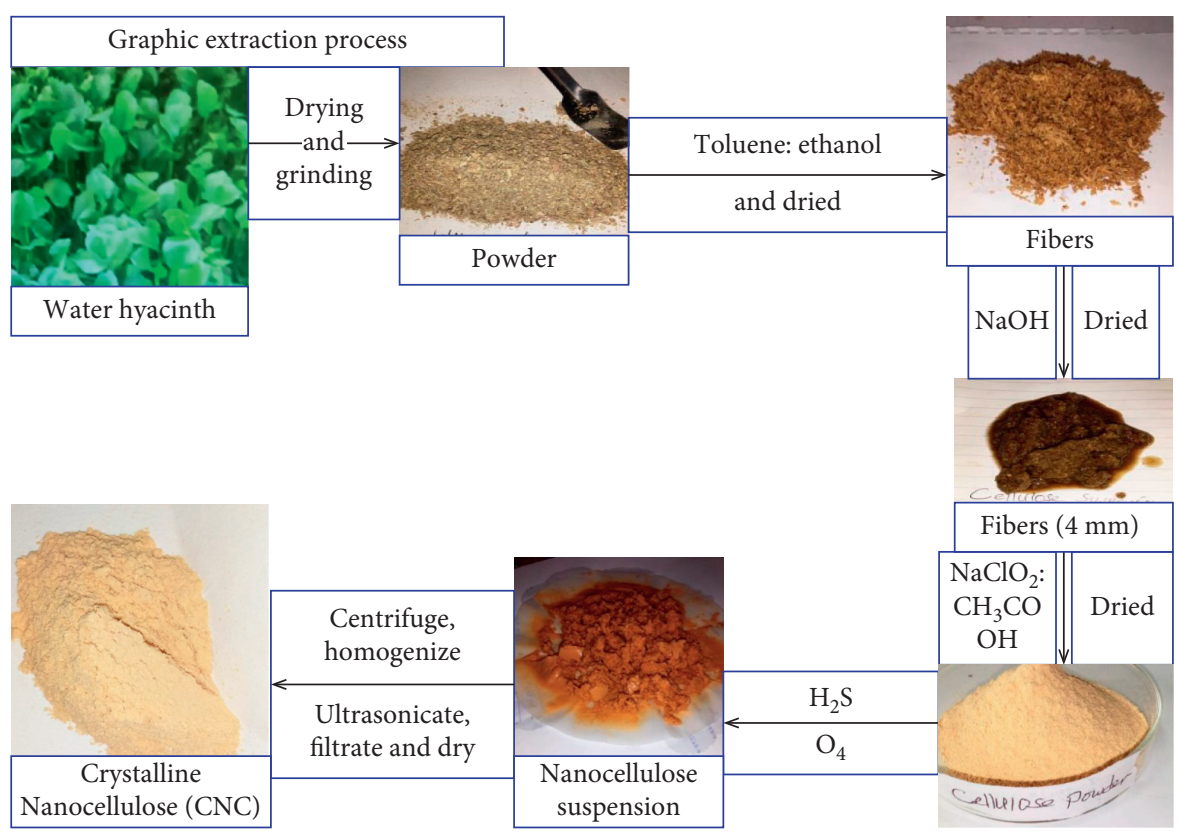

FIGURE 1: Flowchart of CNC preparation from Eichhornia crassipes.

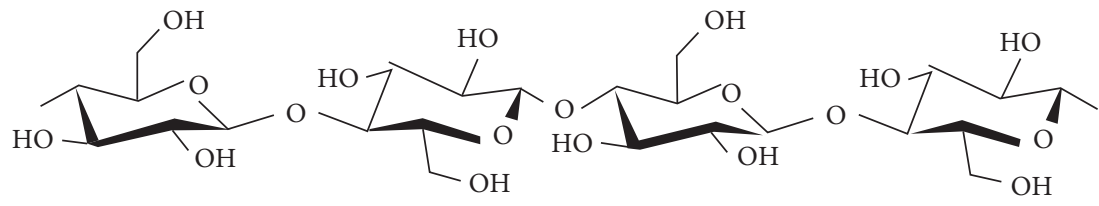

$\mathrm{CNC}$<smiles>O=C1C=CC=CC1=O</smiles>

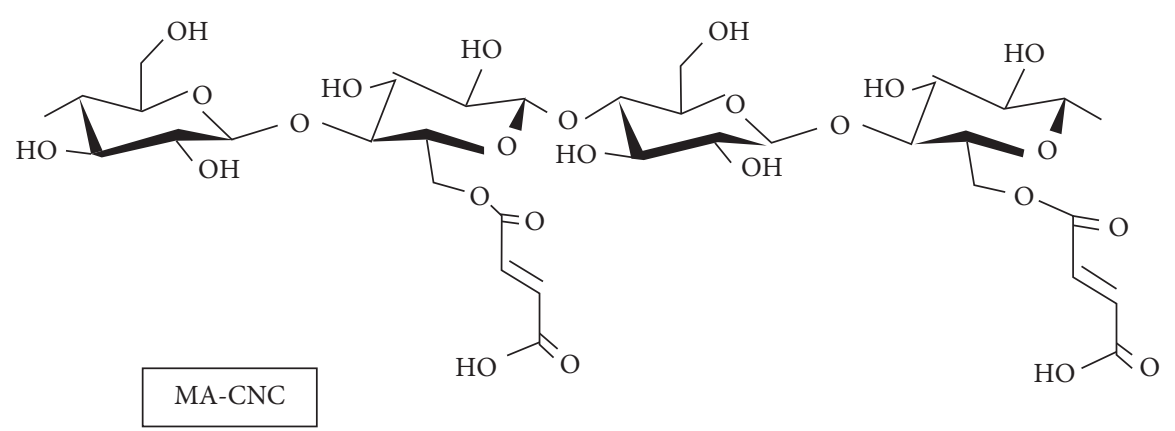

FIGURE 2: Esterification of cellulose nanocrystalline (CNC) by using maleic anhydride (MA).

defined as the ratio between the mass of adsorbent $\mathrm{CNC}$ and MA-CNC adsorbents (g) to the initial volume of the water sample $(L)$. Both the initial and the optimum amounts of $\mathrm{Cd}(\mathrm{II})$ ions were used to measure the percentage of $\mathrm{Cd}(\mathrm{II})$ ions removal as follows:

$$
\% \mathrm{Cd}(\mathrm{II}) \text { ion removal }=\frac{C_{i} \mathrm{Cd}(\mathrm{II})-C_{e} \mathrm{Cd}(\mathrm{II})}{C_{i} \mathrm{Cd}(\mathrm{II})} \times 100 \% .
$$

The thermodynamic study of the adsorption process was studied by considering the fundamental thermodynamic parameters such as a change in Gibbs free energy $(\Delta G)$, change in enthalpy $(\Delta H)$, and change in entropy $(\Delta S)$ values $[34,35]$. Therefore, the thermodynamics of the removal of $\mathrm{Cd}(\mathrm{II})$ ions was performed by using all the optimum values of predetermined parameters, such as solution $\mathrm{pH}$, sorbent dosage, $\mathrm{Cd}(\mathrm{II})$ ions initial concentration, and agitation speed by varying the temperature range from 20 to $45^{\circ} \mathrm{C}$. 
2.5.2. Adsorption Kinetics. The Cd(II) ion remediation kinetic process from $\mathrm{WW}$ was performed using the contact time ranging from 30 to $180 \mathrm{~min}$ by making all parameters (solution $\mathrm{pH}$, sorbent dose, shaking speed, and $\mathrm{Cd}(\mathrm{II})$ ions initial concentration) at optimum value.

2.6. Regeneration Experiment. For regeneration experiments, the modified (MA-CNC) sorbent was selected because of the high removal efficiency of $\mathrm{Cd}(\mathrm{II})$ ions from WW. The experiments were conducted after desorption of $\mathrm{Cd}(\mathrm{II})$ ions by the addition of $0.5 \mathrm{~g}$ MA-CNC adsorbent to a flask containing $10 \mathrm{~mL}$ of $0.1 \mathrm{M} \mathrm{HCl}$ solution. Then, this mixture was sonicated and centrifuged to separate the adsorbent from the mixture. The separated MA-CNC sorbent was then washed with deionized water four times, filtered, and dried. The regenerated adsorbent was reused for at least $13^{\text {th }}$ frequent sequences as adsorbent without any significant efficient loss.

\section{Results and Discussion}

3.1. Characterization. Both the $\mathrm{CNC}$ and $\mathrm{MA}-\mathrm{CNC}$ sorbents were characterized by using modern instrumental techniques, such as FTIR, XRD, and SEM. The identification of functional groups and surface characteristics of the asprepared CNM and MA-CNC sorbents were carried out by using FTIR spectroscopy. The spectra of CNC and MA-CNC sorbents prepared with the help of sulfuric acid hydrolysis obtained from the FTIR spectroscopy are shown in Figure 3(a). The results revealed that both $\mathrm{CNC}$ and MACNC have representative broadband around $3355 \mathrm{~cm}^{-1}$ which corresponds to $\mathrm{O}-\mathrm{H}$ free stretching vibration of the $\mathrm{CH}_{2}-\mathrm{OH}$ structure on cellulose I and $\mathrm{OH}$ groups [40]. The spectra located at $2925 \mathrm{~cm}^{-1}$ are as a result of C-H stretching vibration in cellulose $\mathrm{I}$, and the spectra found in zone four at $1735 \mathrm{~cm}^{-1}$ are recognized to the carbonyl functional groups of cellulose I. The peaks detected at $1458 \mathrm{~cm}^{-1}$ are correlated to the $\mathrm{C}-\mathrm{C}$ stretching and/or $\mathrm{CH}_{2}$ symmetric bending in aromatic groups of cellulose $\mathrm{I}$. The peak located at $1058 \mathrm{~cm}^{-1}$ is connected to the C-O-C stretching of cellulose I [41]. Compared with the spectrum of raw $\mathrm{CNC}$, additional peaks observed in the oxidized cellulose nanomaterial (MA-CNC) at $1428 \mathrm{~cm}^{-1}$, referring to the stretching vibration of the ionic carboxylic groups, confirmed the insertion of carboxylic groups on the surface of CNC sorbent. Also, the spectra at $1265-1325 \mathrm{~cm}^{-1}$ are indications of the presence of $\mathrm{C}-\mathrm{O}-\mathrm{C}$ groups on the sorbent. This makes maleic anhydride efficaciously oxidize the adjacent hydroxyl groups of cellulose at locations of carbon numbers 2 and 3 into aldehyde groups, concurrently breaking the corresponding carboncarbon bond of the glucopyranose ring in order to obtain DACNC.

The CNC and MA-CNC sorbent crystalline particle size was determined by using the XRD diffractogram (Figure 3(b)). The crystallographic planes of cellulose I structure were certainly fixed to the peaks attributed at $2 \theta=15.87^{\circ}, 22.50^{\circ}$, and $34.82^{\circ}$ are (110), (110), and (004), respectively [42]. From the XRD patterns, the pristine CNM sorbent has the same peaks as that of the esterified (MACNC) except for the increased degree of crystallinity for the $\mathrm{CNC}$ sorbent (Figure 3(b)). Despite the increased degree of crystallinity for the CNC sorbent, both sorbents undoubtedly displayed the amorphous nature in contrast to $100 \%$ crystallinity because of the polymeric nature of Eichhornia crassipes. The diffractogram of CNC and MA-CNC sorbents has an obvious sharp band focused at $22.50^{\circ}$ attributed to the semicrystalline structure of the cellulose-based sorbents. The functionalized nanocellulose exhibited a reduced percent of crystallinity and broad peak than the raw CNM because of the oxidation of the crystalline region by the addition of maleic anhydride into the raw nanocellulose suspension [43].

Both CNC and MA-CNC sorbent microstructures and surface morphologies were done using SEM instruments (Figures 3(c) and 3(d)). The image from the SEM micrograph shows that both CNM and MA-CNM sorbents were cylindrical rod-like shapes. From the SEM image, MA-CNC sorbent was probable to agglomerate in comparison with $\mathrm{CNC}$ after drying. In MA-CNC adsorbents, the produced carbonyl groups might also encourage the presence of hydrogen bond structures in the MA-CNC sorbents. These variations in biochemical arrangements also caused the variations in surfaces of DACNC $[44,45]$.

Brunauer-Emmett-Teller (BET) data investigation is accomplished according to the BET adsorption isotherm linear equation (4) to determine the specific surface area of $\mathrm{CNC}$ and MA-CNC adsorbents. Its measurement was carried out using $\mathrm{N}_{2}$ gas as an adsorbate at a temperature of $77 \mathrm{~K}$.

$$
\frac{p / p_{o}}{n\left(1-p / p_{o}\right)}=\frac{C-1}{\left(X_{m} C\right)}\left(p / p_{o}\right)+\frac{1}{X_{m} C},
$$

where $P_{\mathrm{o}}$ and $P$ are saturated and partial vapor pressure of $\mathrm{N}_{2}$ gas at equilibrium in $\mathrm{Pa}$, respectively; $n$ is the volume of $\mathrm{N}_{2}$ gas adsorbed at STP in mL; $X_{m}$ is BET monolayer capacity; $C$ is a dimensionless constant associated with the enthalpy of $\mathrm{N}_{2}$ gas adsorption on the adsorbent.

For the well-defined BET monolayer capacity of the nanoparticle materials, the value of $C$ should be $\geq 80$ [46]. Thus, from the given equation (4), it is possible to obtain the $C$ value of $\mathrm{NaIO}_{4}$-NC (188.3 and 190.2) which is $\geq 80$. Figure $4(a)$ indicates the linear plots of $\left[\left(P / P_{o}\right) /\left(n\left(1-P / P_{o}\right)\right)\right]$ versus $P / P_{\mathrm{o}}$ and provides a straight line with the approximate relative pressure ranging from 0.05 to 0.3 . The linear regression value $\left(R^{2}\right)$ obtained from this plot was 0.9985 , which is greater than 0.995 . This result confirms the acceptability level of the $R^{2}$ value. The specific surface area (SSA) in $\mathrm{m}^{2} \cdot \mathrm{g}^{-1}$ is calculated according to

$$
a_{s}=\frac{X_{m} L \sigma_{m}}{m \times 22400},
$$

where $a_{s}$ is the BET specific surface area of the $\mathrm{NaIO}_{4}-\mathrm{NC}$ of mass $m$ in grams, $L$ is the Avogadro constant $\left(6.022 \times 10^{23} \mathrm{~mol}^{-1}\right), \sigma_{m}$ is the molecular adsorptive crosssectional area occupied by $\mathrm{N}_{2}$ gas molecule in the complete monolayer (equal to $0.162 \mathrm{~nm}^{2}$ for $\mathrm{N}_{2}$ gas), and 22400 is the volume occupied by 1 mole of $\mathrm{N}_{2}$ gas at STP, in $\mathrm{mL}$. 


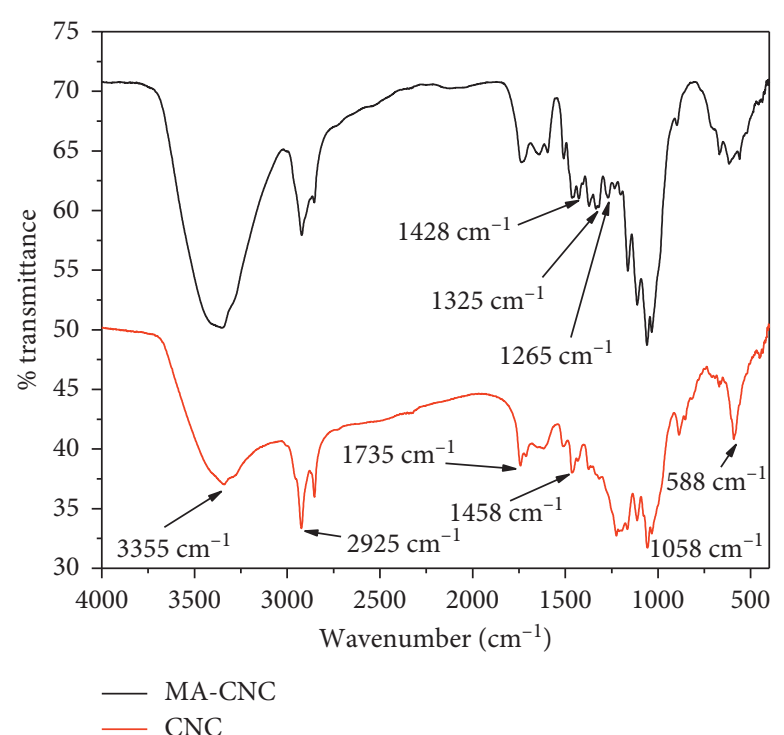

(a)

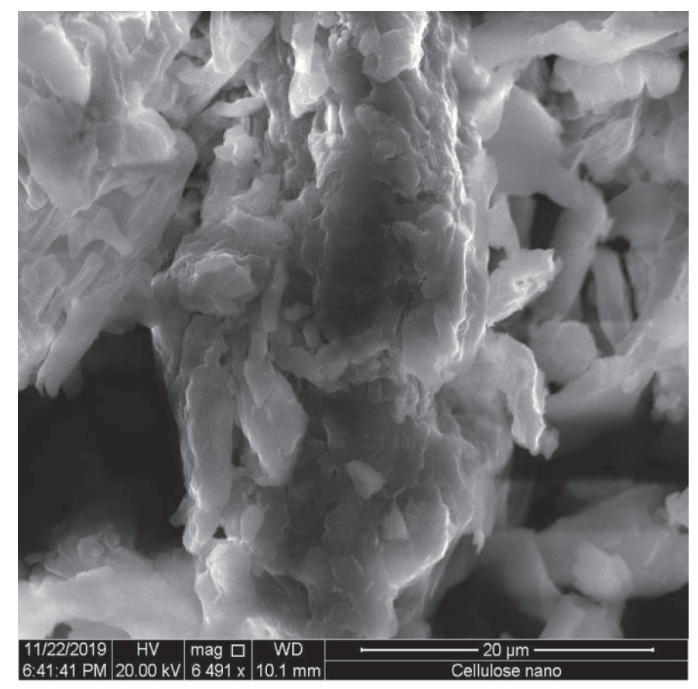

(c)

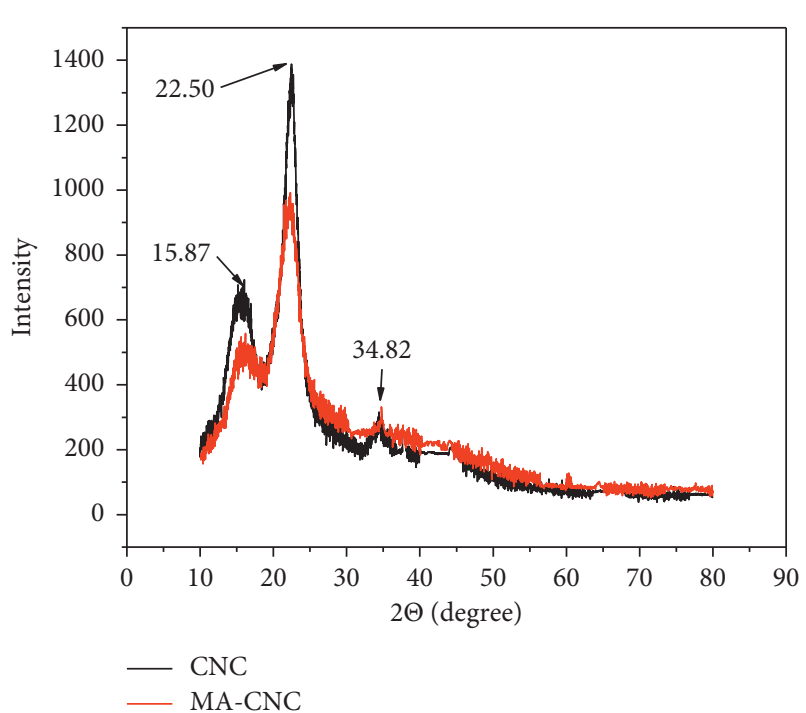

(b)

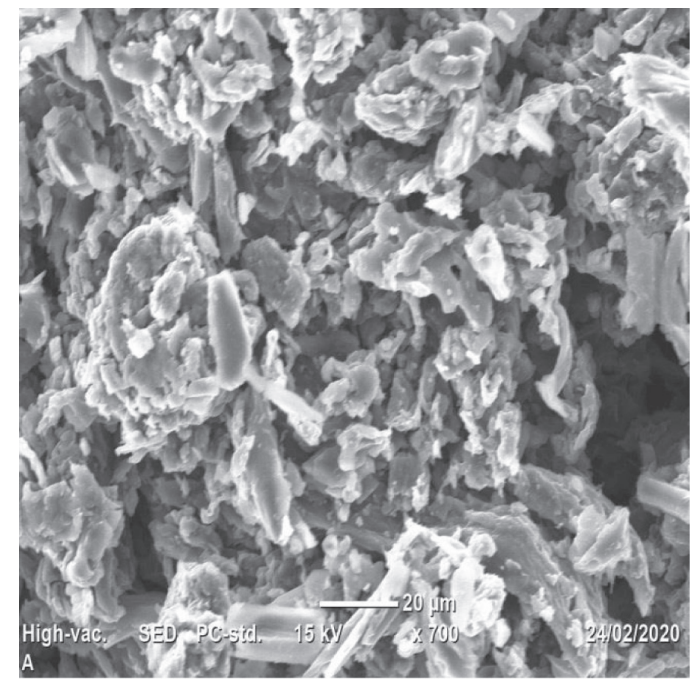

(d)

FIGURE 3: (a) FTIR spectra, (b) XRD pattern, and (c, d) SEM images of CNC and MA-CNC sorbents, respectively.

The BET plot of CNC and MA-CNC sorbents, respectively, in Figure 4(b) has indicated the cylindrical shape model. The symbols used were those given in the 2007 edition of the IUPAC manual [47]. Results indicated that the as-prepared $\mathrm{CNC}$ and MA-CNC adsorbents have a higher SSA of 108.2 and $123.9 \mathrm{~m}^{2} \mathrm{~g}^{-1}$, respectively. Therefore, CNC and MA-CNC adsorbents have shown higher Cd(II) ion adsorption efficiency due to the decrease of the particle size, an increase of specific surface area, and the increase of surface roughness.

3.2. Physicochemical Properties of the WW. The collected WW physicochemical property measurements are performed within 24 hours after collection and given in Table 1. Values for $\mathrm{pH}$ and electrical conductivity were determined in different series and reported as average values of $7.5 \pm 0.05$ and $265 \pm 0.3$, respectively. These results have shown that
WW taken from the run of Modjo Rivers was nearly neutral. Furthermore, the average concentrations of COD, BOD, TP, TIN, nitrate $\left(\mathrm{NO}_{3}^{-}\right),\left(\mathrm{NH}_{4}^{+}\right), \mathrm{Mg}^{2+}, \mathrm{Cu}^{2+}$, and $\mathrm{Cd}^{2+}$ in the WW were $51.4 \pm 0.2,36.75 \pm 0.02,11.44 \pm 0.3,43.05 \pm 0.02$, $5.04 \pm 0.05, \quad 29.5 \pm 0.02, \quad 50.9 \pm 0.6, \quad 0.43 \pm 0.03, \quad$ and $0.12 \pm 0.04$, respectively.

\subsection{Adsorption Studies}

3.3.1. Effects of Contact times. Experiments for contact time effects on the removal of $\mathrm{Cd}(\mathrm{II})$ ions from wastewater were conducted by using the contact times ranging from 30 to $180 \mathrm{~min}$ at optimum CNC and MA-CNC dose of $0.5 \mathrm{~g}$, temperature $(T)$ of $20^{\circ} \mathrm{C}$, and initial Cd(II) ions concentration of $20 \mathrm{mg} \mathrm{L}^{-1}$ (Figure 5(b)). The results have shown that the $\mathrm{Cd}(\mathrm{II})$ ion removal capacity increases by increasing the contact time from 30 to 120 min for both CNC and MA-CNC 


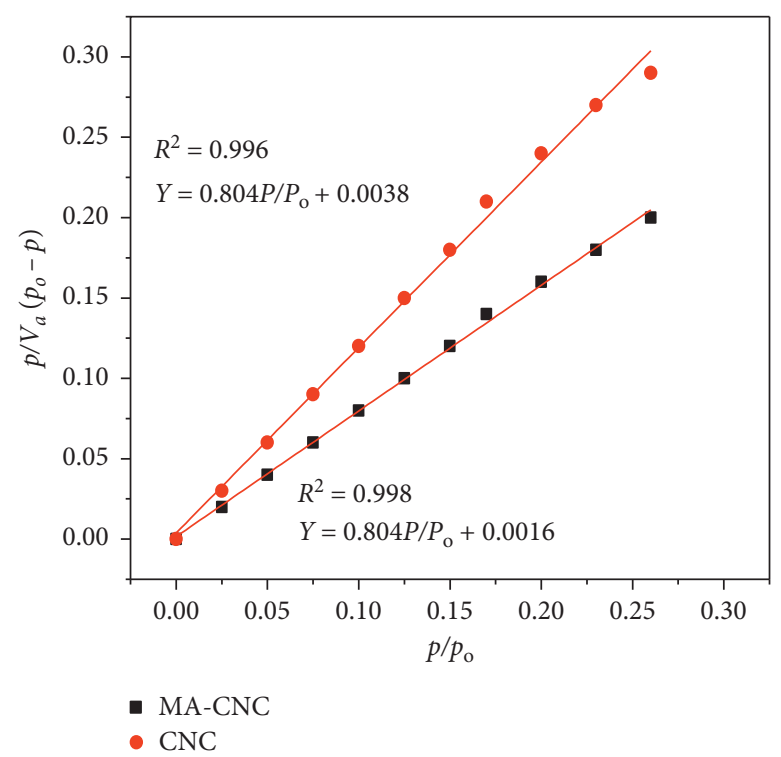

(a)

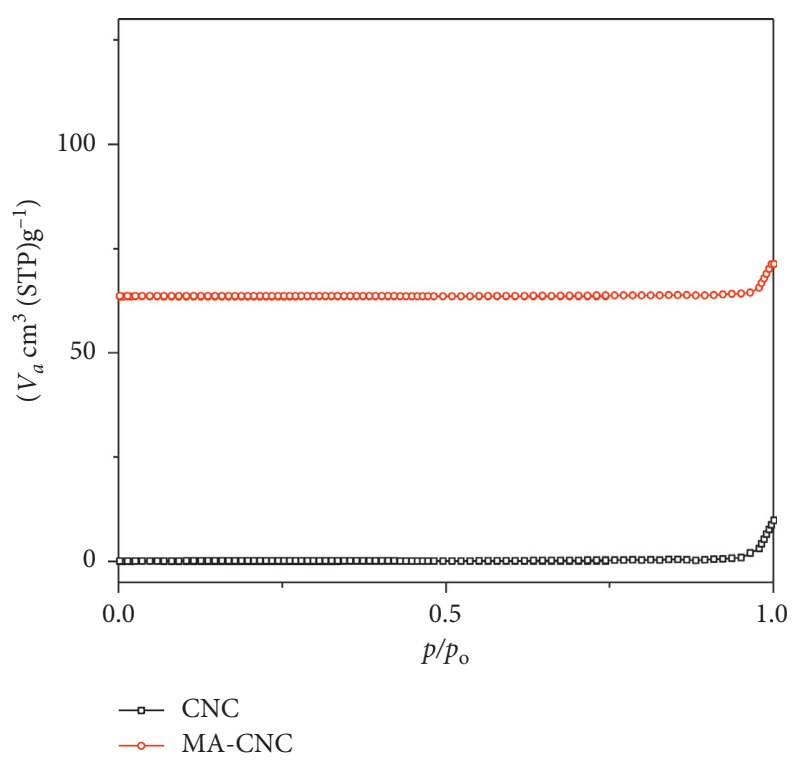

(b)

Figure 4: (a) The linear plot of CNC and MA-CNC and (b) the BET plot of CNC and MA-CNC adsorbents.

TABLe 1: Physicochemical properties of the SERWW used in the study.

\begin{tabular}{lccc}
\hline Parameter & Lowest value & Maximum value & Average \\
\hline $\mathrm{pH}$ & $6.9 \pm 0.05$ & $8.3 \pm 0.05$ & $7.5 \pm 0.05$ \\
$\mathrm{EC}\left(\mu \mathrm{S} \mathrm{cm}{ }^{-1}\right)$ & $260 \pm 0.3$ & $270 \pm 0.3$ & $265 \pm 0.3$ \\
$\mathrm{COD}(\mathrm{mg} / \mathrm{L})$ & $42.25 \pm 0.2$ & $60.5 \pm 0.2$ & $51.4 \pm 0.2$ \\
$\mathrm{BOD}(\mathrm{mg} / \mathrm{L})$ & $30.4 \pm 0.02$ & $42.8 \pm 0.02$ & $36.75 \pm 0.02$ \\
$\mathrm{TIN}(\mathrm{mg} / \mathrm{L})$ & $31.5 \pm 0.02$ & $54.6 \pm 0.02$ & $43.05 \pm 0.02$ \\
$\mathrm{NO}_{3}^{-}(\mathrm{mg} . \mathrm{N} / \mathrm{L})$ & $4.3 \pm 0.05$ & $5.8 \pm 0.05$ & $5.04 \pm 0.05$ \\
$\mathrm{NH}_{4}^{+}(\mathrm{mg} . \mathrm{N} / \mathrm{L})$ & $26.7 \pm 0.02$ & $32.3 \pm 0.02$ & $29.5 \pm 0.02$ \\
$\mathrm{TP}(\mathrm{mg} / \mathrm{L})$ & $10.2 \pm 0.3$ & $12.6 \pm 0.3$ & $11.44 \pm 0.3$ \\
$\mathrm{Mg}^{2+}(\mathrm{mg} / \mathrm{L})$ & $41.5 \pm 0.6$ & $60.3 \pm 0.6$ & $50.9 \pm 0.6$ \\
$\mathrm{Cu}^{2+}(\mathrm{mg} / \mathrm{L})$ & $0.30 \pm 0.03$ & $0.56 \pm 0.03$ & $0.43 \pm 0.03$ \\
$\mathrm{Cd}^{2+}(\mathrm{mg} / \mathrm{L})$ & $0.08 \pm 0.04$ & $0.16 \pm 0.04$ & $0.12 \pm 0.04$ \\
\hline
\end{tabular}

TP: total phosphorus; TIN: total inorganic nitrogen; BOD: biological oxygen demand; COD: chemical oxygen demand.

sorbents because of the increased number of active sites available on the surfaces of $\mathrm{CNC}$ and MA-CNC sorbents. The maximum \% removal (\%R) of $\mathrm{Cd}(\mathrm{II})$ ions of 67.80 and $88.84 \%$ was observed at the optimum contact time of $120 \mathrm{~min}$ for CNC and MA-CNC adsorbents, respectively. After $120 \mathrm{~min}$., the $\mathrm{Cd}(\mathrm{II})$ ions \%R remains unchanged because, with the increased contact time, the ratio of surface active sites to the total metal ions in the solution was low, and hence, all active sites had metal ions in solution and were occupied $[48,49]$. In comparison to MACNC sorbent with $\mathrm{CNC}$, the maximum $\mathrm{Cd}(\mathrm{II})$ ion uptake capabilities were observed for MA-CNC sorbent than CNC because of the increased number of active sites resulting from the esterification reaction of maleic anhydride. This result was in agreement with research reported by Madivoli et al. [49].
3.3.2. Effects of Initial Concentration. The effect of the initial concentration of $\mathrm{Cd}(\mathrm{II})$ ions against quantity adsorbed was conducted by using the optimum quantity of $\mathrm{CNC}$ and MACNC sorbents of $0.5 \mathrm{~g}, \mathrm{pH}$ of 8 , and the contact time of $120 \mathrm{~min}$ (Figure 5(a)). At the starting point, the Cd(II) ion removal process was very rapid until the optimum value of $20 \mathrm{mg} / \mathrm{L}$. At this stage, the ratio of surface active sites to the total metal ions in the solution was high, and hence, all $\mathrm{Cd}(\mathrm{II})$ ions are attracted to the surfaces of CNC and MACNC adsorbents [50]. At the optimum initial Cd(II) ion concentration of $20 \mathrm{mg} \mathrm{L}^{-1}$, both adsorbents clearly have shown higher $\mathrm{Cd}(\mathrm{II})$ ions \%R of 64.91 and 88.44 from WW by $\mathrm{CNC}$ and MA-CNC adsorbents, respectively. Additionally, the higher \% $\mathrm{R}$ of $\mathrm{Cd}(\mathrm{II})$ ions is evidently detected for MA-CNC sorbent relative to $\mathrm{CNC}$ adsorbent. This is because the presence of extra active sites on the MA-CNC adsorbent resulted from the esterification reaction of $\mathrm{CNC}[51,52]$.

3.3.3. Effects of Adsorbent Dose and Temperature. The effects of CNC and MA-CNC dose on the \% R of Cd(II) ions from WW at different temperatures, $T=20,30$, and $45^{\circ} \mathrm{C}$, were investigated, and the results are shown in Figure 5. Results have indicated that $\mathrm{Cd}(\mathrm{II})$ ion uptake ability was increased by increasing the CNC and MA-CNC adsorbent dose. This publicized that the uptake sites become unsaturated during the adsorption reaction, whereas the number of active surface areas available for the adsorption site increased by increasing the $\mathrm{CNC}$ and MA-CNC adsorbent dose. The maximum \%R of 70.3 and 90.4 was observed at optimum $\mathrm{CNC}$ and MA-CNC adsorbent dose of $0.5 \mathrm{~g}$ and optimum temperature of $20^{\circ} \mathrm{C}$, respectively. After this dose value, the $\% \mathrm{R}$ becomes unchanged because of the particle aggregation, which would lead to a decrease in the total surface area of the adsorbent [53]. A higher $\% \mathrm{R}$ of $90.4 \%$ was observed by using functionalized adsorbent than $\mathrm{CNC}$ because the 


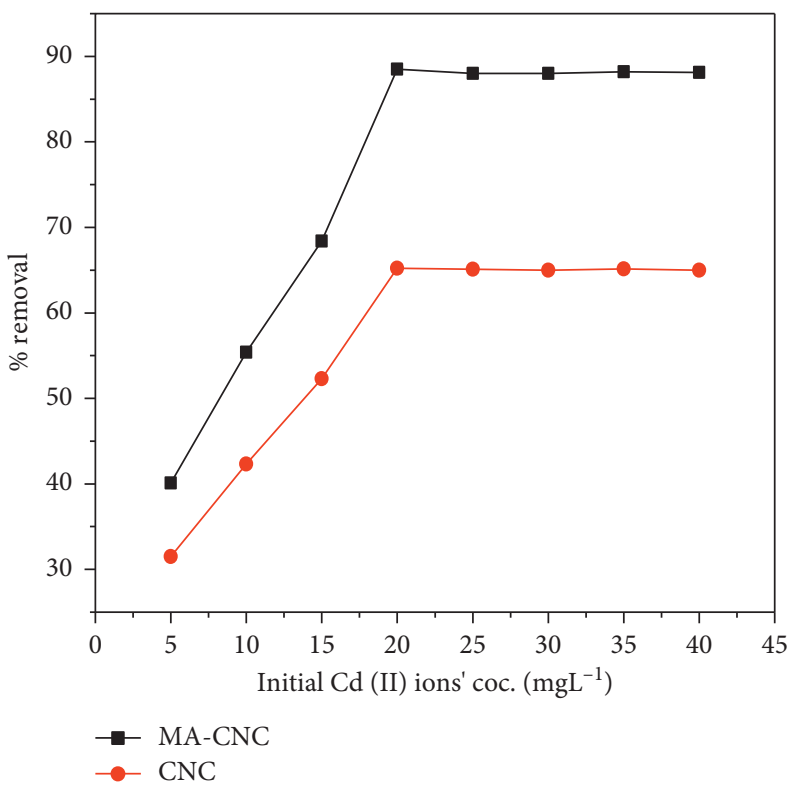

(a)

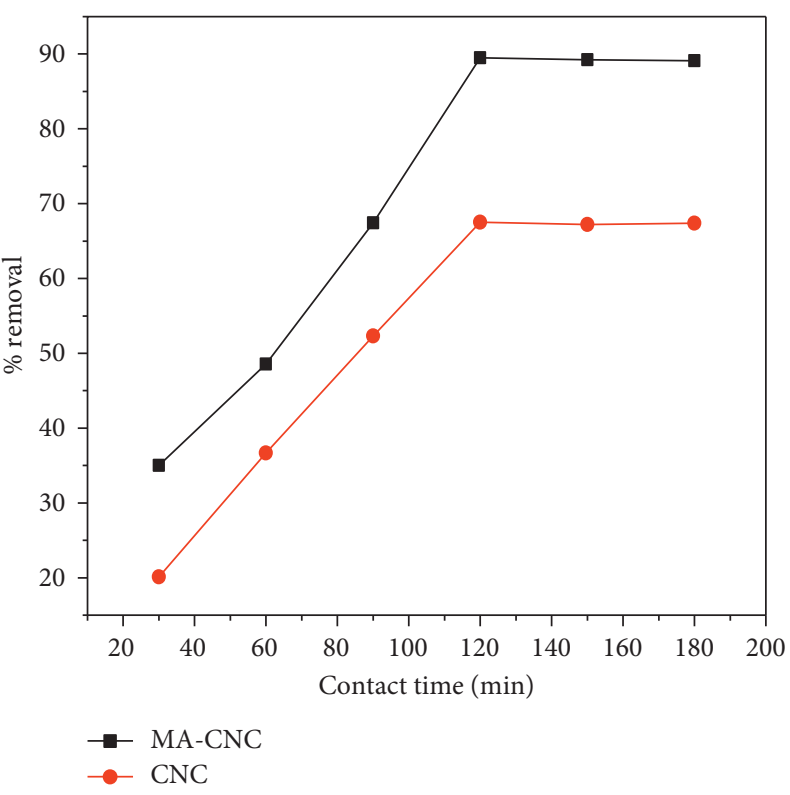

(b)

Figure 5: The effect of initial concentration (a) and contact time (b) for the removal of Cd(II) ions from wastewater, respectively, at an optimum temperature of $20^{\circ} \mathrm{C}$, adsorbent dosage of 0.5 , solution $\mathrm{pH}$ of 8 , and agitation speed of $250 \mathrm{rpm}$.

esterification reaction provides the extra-functional groups on the adsorbent surface that make the functionalized adsorbent most active to adsorb Cd(II) ions onto the surface than a pristine one.

Figures 6(a) and 6(b) show the temperature effects on the $\% \mathrm{R}$ of $\mathrm{Cd}(\mathrm{II})$ ions from WW by $\mathrm{CNC}$ and MA-CNC sorbents. Results have shown that the decreased \% $\mathrm{R}$ of $\mathrm{Cd}(\mathrm{II})$ ions was observed at the higher temperature of $45^{\circ} \mathrm{C}$. This is because, at increased temperature, the slow rate of the chemisorption processes prevents the $\mathrm{Cd}(\mathrm{II})$ ions to react with the active sites of the sorbent surface for increased $\% \mathrm{R}$ of Cd(II) ions from wastewater [54]. For both CNC and MA$\mathrm{CNC}$ adsorbents, the maximum \% $\mathrm{R}$ of $70.3 \%$ and $90.4 \%$ was detected at the optimum dose and temperature of $0.5 \mathrm{~g}$ and $20^{\circ} \mathrm{C}$, respectively. Furthermore, the higher $\% \mathrm{R}$ of $\mathrm{Cd}(\mathrm{II})$ ions was observed by using MA-CNC sorbents than $\mathrm{CNC}$ sorbents due to the presence of extra-functional groups on the modified one [55].

3.3.4. Effects of Solution $p H$. The effect of solution $\mathrm{pH}$ on $\mathrm{Cd}(\mathrm{II})$ ions removal from WW was performed by using $\mathrm{pH}$ values ranging from 2 to 12. As shown in Figure 7(b), both $\mathrm{CNC}$ and MA-CNC adsorbents show the increasing removal abilities in the solution $\mathrm{pH}$ ranging from 2 to 8 . The maximum \% R for both CNC and MA-CNC adsorbents was 70.3 and $89.9 \%$, respectively. At decreased solution $\mathrm{pH}$ amounts, the interaction of $\mathrm{Cd}(\mathrm{II})$ ions with adsorbents is declined because of the competition of $\mathrm{H}^{+}$ions on the surfaces of the adsorbents [50]. Conversely, at the increased solution $\mathrm{pH}, \mathrm{Cd}(\mathrm{II})$ ions binding to the $\mathrm{CNC}$ and MA-CNC adsorbents surfaces rise until the equilibrium $\mathrm{pH}$ of 8 . After the optimum $\mathrm{pH}$ value of 8 , the $\% \mathrm{R}$ becomes declined due to the presence of increased amounts of $\mathrm{OH}^{-}$ions in WW. The increased $\mathrm{OH}^{-}$ions depict the formation of soluble hydroxyl complexes. Furthermore, at a higher alkaline $\mathrm{pH}$ value, the $\mathrm{Cd}(\mathrm{II})$ ions precipitate as $\mathrm{Cd}(\mathrm{OH})_{2}$. Figure 7 (a) also shows that the higher \% $\mathrm{R}$ of $\mathrm{Cd}(\mathrm{II})$ ions was observed by MA-CNC adsorbent than $\mathrm{CNC}$ sorbents at the optimum solution $\mathrm{pH}$ value of 8 . The differences in the reported $\% \mathrm{R}$ for the $\mathrm{Cd}(\mathrm{II})$ ions were related to the occurrence of additional functional groups in the structure of MA-CNC adsorbents with different affinity to $\mathrm{Cd}(\mathrm{II})$ ions than $\mathrm{CNC}$ sorbent [56].

3.3.5. Effects of Agitation Speed. The effect of agitation speed on the removal of $\mathrm{Cd}(\mathrm{II})$ ions is shown in Figure 7(b). Initially, the agitation speed was slow, but as the agitation speed was increased subsequently, a rapid increase in the removal capability of $\mathrm{Cd}(\mathrm{II})$ ions was observed. This is due to the presence of more active sites existing on the binding surface of the adsorbent that is ready to adsorb Cd(II) ions [57]. Thus, the \%R capacity of $\mathrm{Cd}(\mathrm{II})$ ions by MA-CNC adsorbent was increased from 72.2 to $88.55 \%$ as the agitation speed was increased from 100 to $250 \mathrm{rpm}$. In the same way, the $\mathrm{Cd}(\mathrm{II})$ ion \% $\mathrm{R}$ capability of the CNC sorbent was increased from 34.65 to $67.17 \%$ as the agitation speed was increased from 100 to $250 \mathrm{rpm}$ (Figure 7(b)). From this point of view, the \%R capability of CNC adsorbent was low compared to MA-CNC adsorbent removal capability. This higher \% R capability observed by MA-CNC adsorbent is due to the presence of more accessible surfaces resulting from the addition of maleic anhydride into the CNC. For both sorbents, the maximum Cd(II) ion \%R capability was obtained at the optimum agitation speed of $250 \mathrm{rpm}$. This result was in agreement with the study reported by Mahmood et al. [58]. Generally, an increase in the speed of agitation speed resulted in outstanding pollutant uptake capabilities and the 


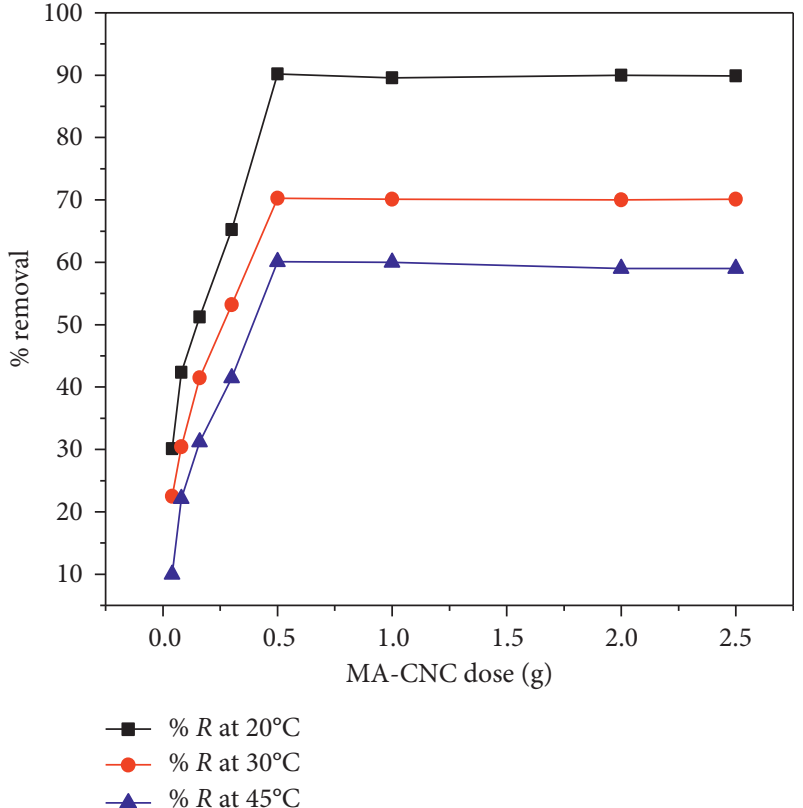

(a)

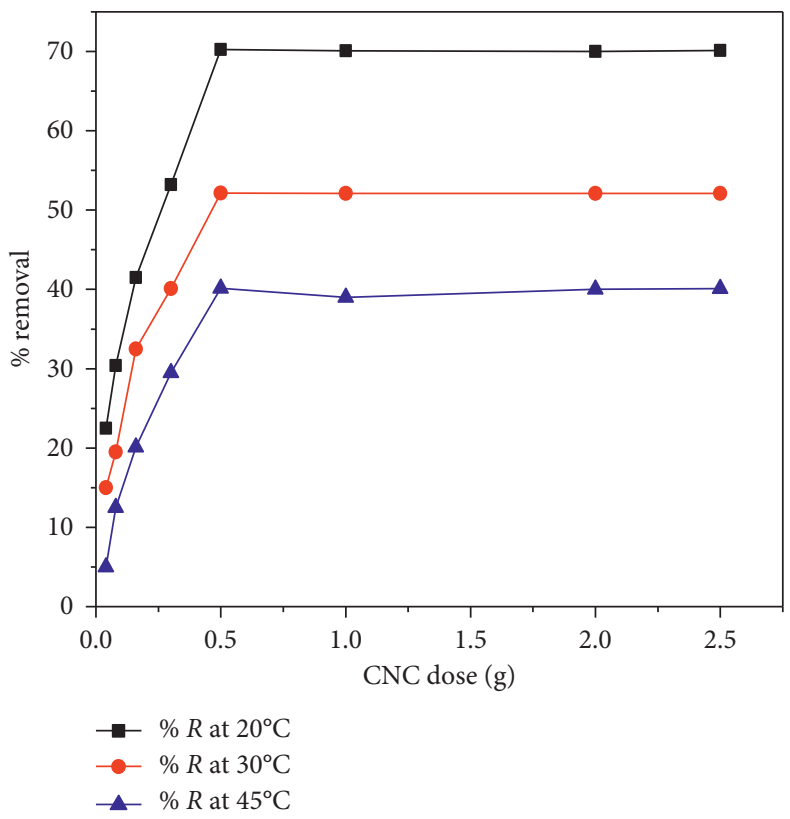

(b)

Figure 6: (a, b) Effects of adsorbent dose at different temperatures $\left(20,30\right.$, and $\left.45^{\circ} \mathrm{C}\right)$ for $\mathrm{Cd}(\mathrm{II})$ ions' remediation using CNC and MA-CNC adsorbents, respectively, at an optimum contact time of $120 \mathrm{~min}$, agitation speed of $250 \mathrm{rpm}, \mathrm{pH}$ of 8 , and initial concentration of $20 \mathrm{mg} / \mathrm{L}$.

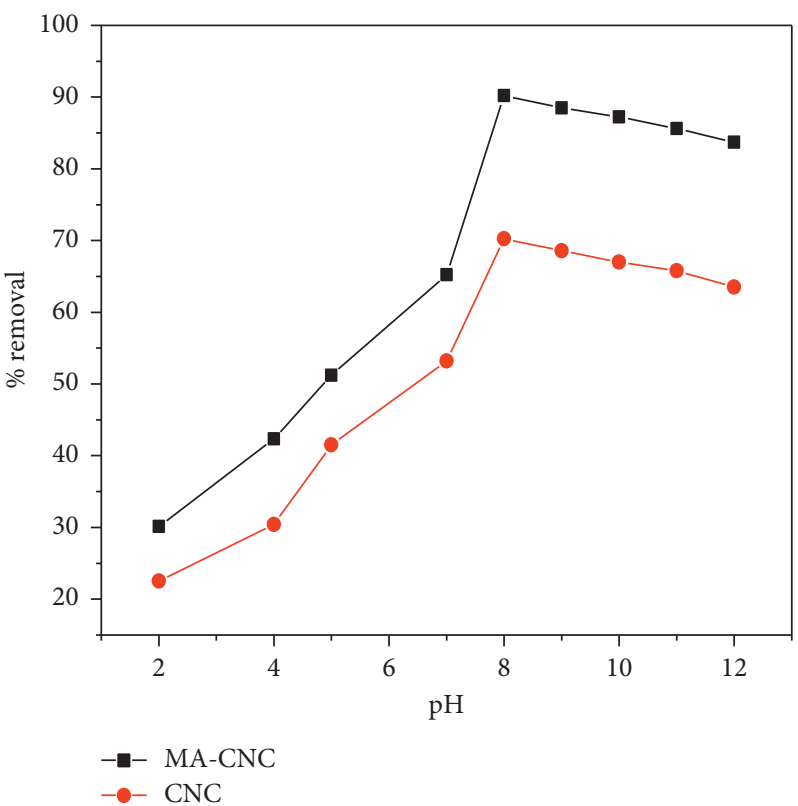

(a)

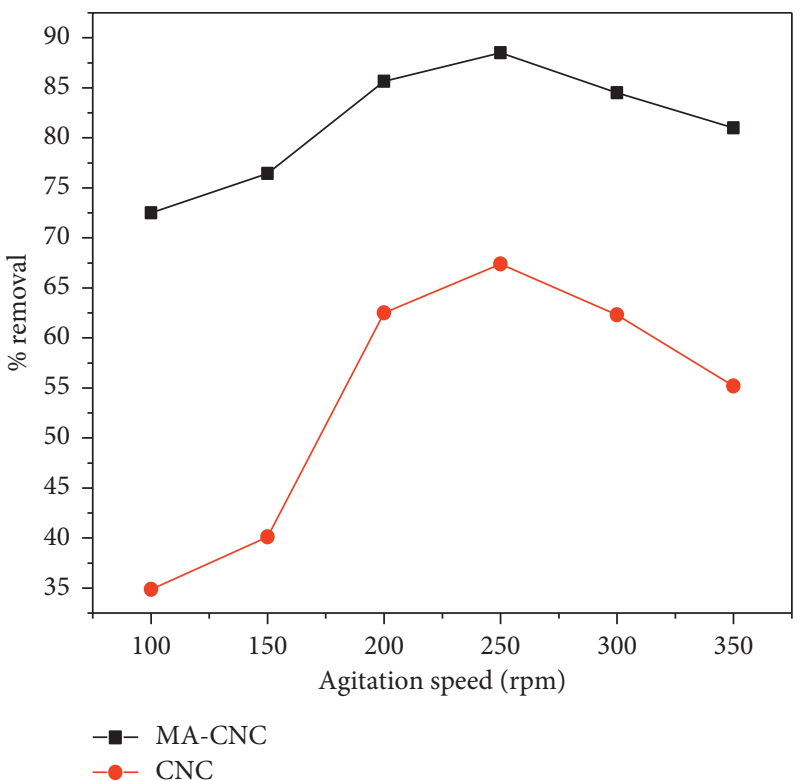

(b)

FIGURE 7: The effect of $\mathrm{pH}$ (a) and agitation speed (b) for the removal of Cd(II) ions from wastewater at an optimum initial concentration of $2 \mathrm{mg} / \mathrm{L}$, contact time of $120 \mathrm{~min}$, temperature of $20^{\circ} \mathrm{C}$, and adsorbent dosage of $0.5 \mathrm{~g}$, respectively.

agitation helps in overcoming the resistance of external mass transfer.

3.4. The Chemistry of Wastewater. Table 1 indicates the summary of the assessment carried out to determine the consequences of wastewater chemistry on the $\% R$ of $\mathrm{Cd}(\mathrm{II})$ ions. Experiments were performed using wastewater samples containing both synthetic and real wastewater at variable levels. Trials were performed in triplicate and reported as average values. From the experiments, the values for $\mathrm{pH}$, $\mathrm{COD}, \mathrm{BOD}, \mathrm{Cl}^{-}, \mathrm{SO}_{4}^{-}, \mathrm{Fe}^{2+}, \mathrm{Ca}^{2+}, \mathrm{Mg}^{2+}$, and $\left(\mathrm{Cu}^{2+}\right)$ present in $\mathrm{WW}$ were determined using replicate of experiments and reported as the average values. The $\% \mathrm{R}$ of the $\mathrm{Cd}(\mathrm{II})$ ions 
from both synthetic and real wastewater is represented in Figure 8. From the findings, it was possible to see that the removal processes were negatively affected by the presence of cations and anions in real wastewater. The lowering of the $\% \mathrm{R}$ of $\mathrm{Cd}(\mathrm{II})$ ions in the real wastewater has resulted from the competition of cations and anions for the active sites in the real wastewater. The consequence of competing ions diminishes the interaction of fresh surfaces on MA-CNM adsorbent and the decreased \% $\mathrm{R}$ of $\mathrm{Cd}(\mathrm{II})$ ions was observed [59]. Results indicated that the \% $\mathrm{R} \mathrm{Cd(II)} \mathrm{ions} \mathrm{from} \mathrm{WW}$ were found to be 99.9 and $89.5 \%$ for the synthetic and real wastewater, respectively, by MA-CNC adsorbent.

3.5. Adsorption Isotherms. To appreciate the mechanism of $\mathrm{Cd}(\mathrm{II})$ ions uptake by $\mathrm{CNC}$ and $\mathrm{MA}-\mathrm{CNC}$ adsorbents, Langmuir (equation (7)) and Freundlich (equation (8)) adsorption isotherms are investigated and presented in Figures 9(a) and 9(b), respectively. Table 2 shows the corresponding parameter values and the correlation coefficient $\left(R^{2}\right)$ values, obtained from each plot. Higher $R^{2}$ values for both Langmuir and Freundlich isotherms have shown that both Langmuir and Freundlich isotherm models better fit the isothermal uptake data. That means, evidently, both of these isotherms describe the distribution of the $\mathrm{Cd}(\mathrm{II})$ ions between the liquid and solid stages conferring to prospects connected to the heterogeneity or homogeneity of the adsorbent surface, the category of coverage, and the prospect of contact between the $\mathrm{Cd}$ (II) ions. This suggested that the surface of CNC and MA-CNC adsorbents was heterogeneous and physically compatible with monolayer adsorption and the adsorption process was favorable. Moreover, strong electrostatic interactions were formed between the Cd(II) ions and the surfaces of adsorbents [60]. The favorability of the uptake process was due to the $n$ value that lies between 1 and 10 , and the strong interactions between the adsorbates and surfaces of the adsorbents were due to the fact that 1 / $n<1$. The fundamental nature of the Langmuir model could be also determined by a dimensionless equilibrium parameter $\left(R_{L}\right)$, and its value was calculated by using equation (6). The values ( 0.104 and 0.602$)$ of $R_{L}<1$ suggested that the uptake process of $\mathrm{Cd}$ (II) ions by both CNC and MA-CNC was a favorable process. Moreover, Table 2 shows that the maximum uptake capacity of both $\mathrm{CNC}$ and MA-CNC adsorbents was 75.76 and $215.52 \mathrm{mg} / \mathrm{g}$, respectively.where $q_{\max }$ is the maximum removal capability of $\mathrm{Cd}(\mathrm{II})$ ions per unit mass of adsorbent $\left(\mathrm{mg} \mathrm{g}^{-1}\right), k_{f}$ is the adsorption capability of the CNC and MA-CNC sorbents $\left(\mathrm{Lmg}^{-1}\right), b$ is the Langmuir constant $\left(\mathrm{Lmg}^{-1}\right)$, and $n$ is the binding intensity. $T$ is the absolute temperature in Kelvin, $R$ is the ideal gas constant $\left(8.314 \mathrm{~J} \mathrm{~mol}^{-1} \mathrm{~K}^{-1}\right)$, and $k_{C}$ is the equilibrium constant calculated by multiplying the $\mathrm{Cd}(\mathrm{II})$ molar weight with Langmuir constant $(b)$.

$$
\begin{aligned}
& \frac{C_{e}}{Q_{e}}=\frac{1}{b Q_{\max }}+\frac{C_{e}}{Q_{\max }}, \\
& R_{L}=\frac{1}{1+b C_{0}},
\end{aligned}
$$

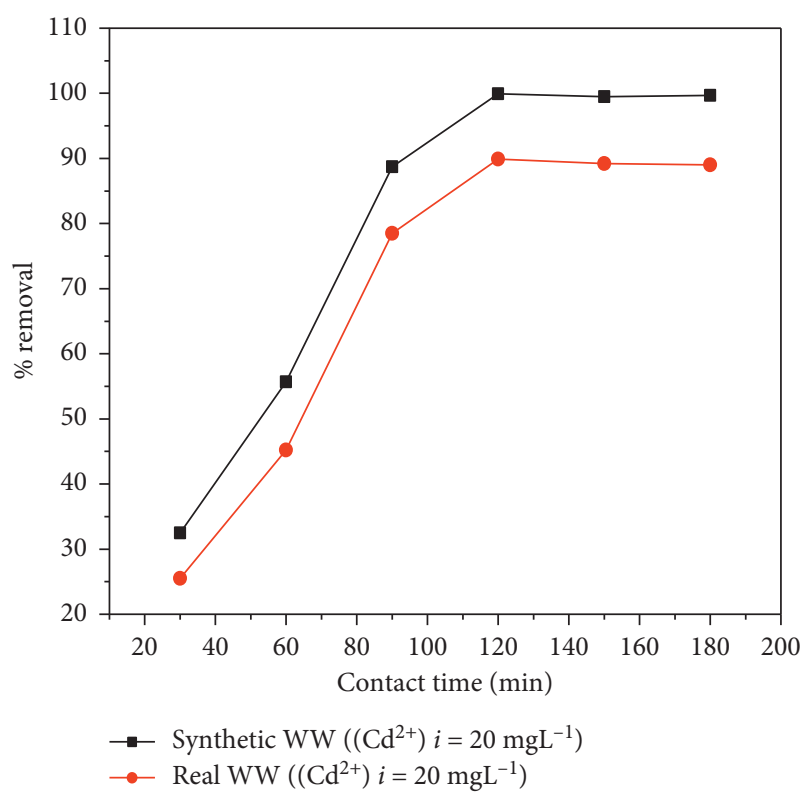

Figure 8: The effects of wastewater chemistry for both synthetic and real wastewater on the percent removal of Cd(II) ions at $20 \mathrm{mg} /$ $\mathrm{L}$ and $20^{\circ} \mathrm{C}$ by using MA-CNC adsorbent.

$$
\begin{aligned}
\log q_{e} & =\log k_{f}+\frac{1}{n} \log C_{e}, \\
\Delta G^{\mathrm{o}} & =-R T \ln k_{C},
\end{aligned}
$$

The thermodynamic study of the Cd(II) ion removal process was conducted using the standard thermodynamic parameter, such as Gibbs free energy $\left(\Delta G^{\circ}\right)$. The Gibbs free energy $\left(\Delta G^{\circ}\right)$ of the $\mathrm{Cd}(\mathrm{II})$ ion adsorption by CNC and MA$\mathrm{CNC}$ was calculated using equation (9). Table 2 presents the calculated Gibbs free energy values of Cd(II) ions. The values of this thermodynamic parameter were determined at temperatures of 20,30 , and $45^{\circ} \mathrm{C}$; the optimum temperature was found to be $20^{\circ} \mathrm{C}$. The higher value of $\Delta G^{\circ}$ change occurred at the operational temperature of $25^{\circ} \mathrm{C}$. This suggests that the adsorption efficiency increases by decreasing the temperature, and the negative value for $\Delta G^{\circ}$ confirms that the removal process of $\mathrm{Cd}(\mathrm{II})$ ions was spontaneous and feasible.

3.6. Uptake Kinetics. The kinetics of Cd(II) ion removal by $\mathrm{CNC}$ and MA-CNC sorbents is established using linearized pseudo-first-order (PFO) (equation (10)) and pseudo-second-order (PSO) (equation (11)), respectively, and given in Figure 10.

$$
\begin{aligned}
\log \left(q_{e}-q_{t}\right) & =\log q_{e}-\frac{K_{1} t}{2.303} \\
\frac{t}{q_{t}} & =\frac{1}{K_{2} q_{e}^{2}}+\frac{t}{q_{e}}
\end{aligned}
$$

The $R^{2}$ value obtained using the PFO kinetic model was too poor at both the initial removal stage and final removal 


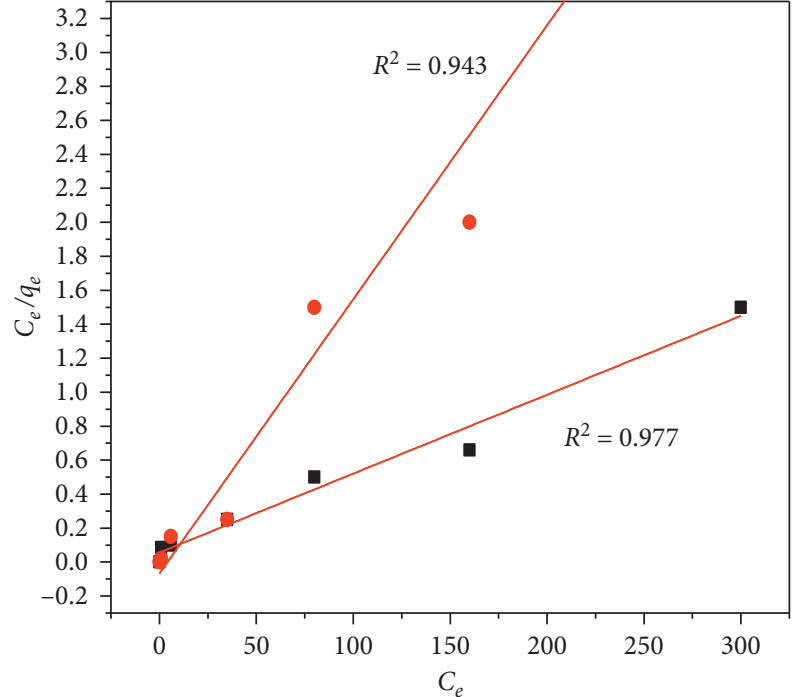

MA-CNC

- $\mathrm{CNC}$

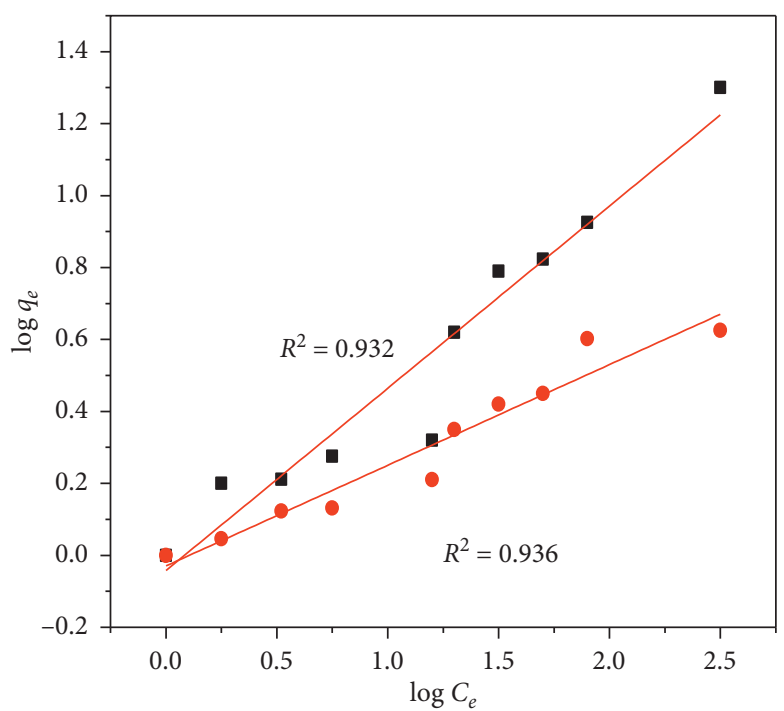

$\mathrm{MA}-\mathrm{CNC}$

- $\mathrm{CNC}$

(a)

(b)

FIgURE 9: Langmuir (a) and Freundlich (b) adsorption isotherm for the removal of $\mathrm{Cd}(\mathrm{II})$ ions, respectively, at $C_{i}=30 \mathrm{mg} / \mathrm{L}, \mathrm{pH}=6$, adsorbent dose $=1 \mathrm{~g}$, contact time $=120 \mathrm{~min}$, and agitation speed $=250 \mathrm{rpm}$.

TABle 2: Langmuir and Freundlich isotherm constants for Cd(II) ion adsorption by CNC and MA-CNC sorbent at $25^{\circ} \mathrm{C}$.

\begin{tabular}{lccccccc}
\hline Adsorption isotherm & \multicolumn{3}{c}{ Langmuir model } & \multicolumn{3}{c}{ Freundlich model } \\
Adsorbents & $Q_{\max }(\mathrm{mg} / \mathrm{g})$ & $b$ & $R_{L}$ & $R^{2}$ & $k_{f}$ & $n$ & $R^{2}$ \\
\hline CNC & 75.76 & 0.43 & 0.104 & 0.977 & 0.93 & 3.57 & 0.936 \\
MA-CNC & 215.52 & 0.083 & 0.602 & 0.977 & 0.91 & 1.97 & 0.932 \\
\hline
\end{tabular}

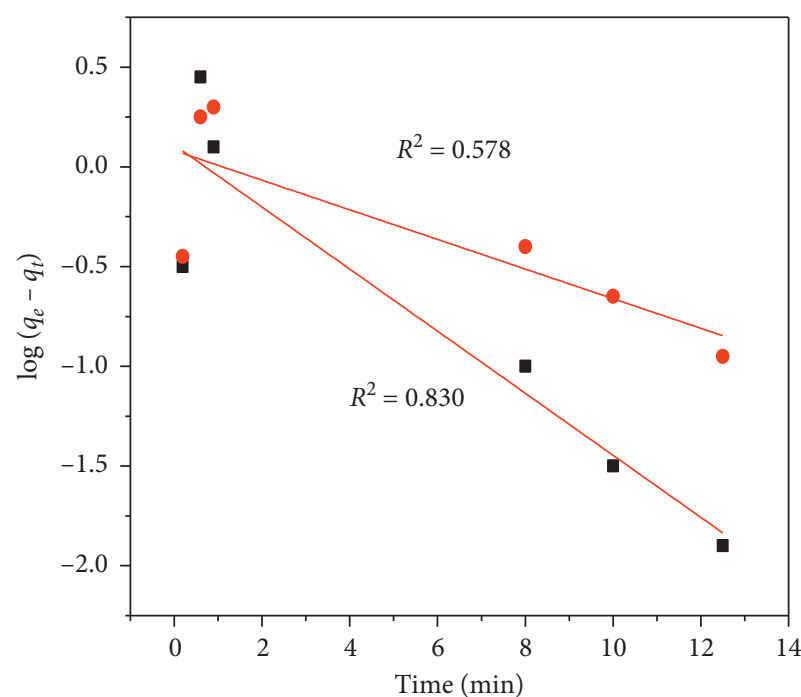

- MA-CNC

- $\mathrm{CNC}$

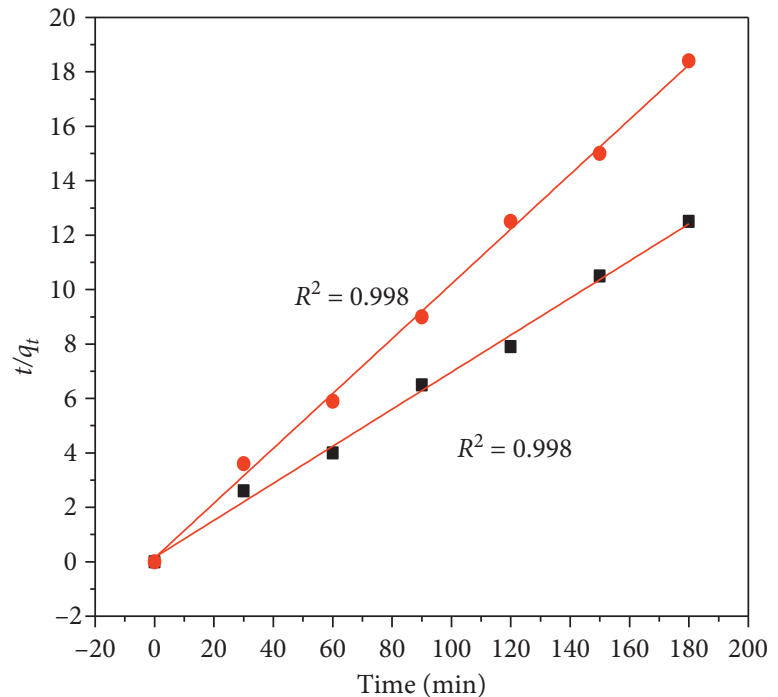

- MA-CNC

- $\mathrm{CNC}$

(a)

(b)

Figure 10: Plot of the PFO (a) and PSO (b) model (at $C_{0}=30 \mathrm{mg} / \mathrm{L}, \mathrm{pH}=6$, adsorbent dose $=1 \mathrm{~g}$, contact time $=120 \mathrm{~min}$, and agitation speed $=250 \mathrm{rpm}$ ) for $\mathrm{Cd}(\mathrm{II})$ ion removal, respectively. 
TABLE 3: The values of parameters and correlation coefficients of pseudo-second-order (PFO) and pseudo-second-order (PSO) kinetics.

\begin{tabular}{lccccccrr}
\hline \multirow{2}{*}{ Kinetics } & \multicolumn{3}{c}{ PFO } & \multicolumn{3}{c}{ PSO } \\
& $q_{e .}$ cal. $(\mathrm{mg} / \mathrm{g})$ & $q_{e .}$ exp. $(\mathrm{mg} / \mathrm{g})$ & $K_{1}$ & $R^{2}$ & $q_{e .}$ cal. $(\mathrm{mg} / \mathrm{g})$ & $q_{e .}$ exp. $(\mathrm{mg} / \mathrm{g})$ & $K_{2}$ & $R^{2}$ \\
\hline CNC & 1.04 & 2.06 & 0.16 & 0.578 & 9.93 & 9.37 & 0.074 \\
MA-CNM & 1.29 & 3.23 & 0.340 & 0.830 & 14.68 & 0.998 \\
\hline
\end{tabular}

stage because the experimental $q_{e}$ value is much different from the calculated $q_{e}$ value for both sorbents. This phenomenon indicates that the adsorption kinetics does not follow this model. Therefore, Figures 10(a) and 10(b) designate a representative fitness of the data corresponding to PSO for $\mathrm{Cd}(\mathrm{II})$ ion adsorption by $\mathrm{CNC}$ and $\mathrm{MA}-\mathrm{CNC}$ sorbents, and this suggests that the adsorption process was more chemisorption. This result was in agreement with the research reported by Priyadarshini et al. [60] on kinetics, thermodynamics, and isotherm studies on adsorption of eriochrome black- $\mathrm{T}$ from aqueous solution using Rutile $\mathrm{TiO}_{2}$. Furthermore, this result was in agreement with the research reported by Tsade et al. [61] on $\mathrm{Pb}$ (II) ion remediation using $\mathrm{Fe}-\mathrm{Al}-\mathrm{MC}$ nanocomposite. The kinetic data are provided in Figures 7 (a) and $7(\mathrm{~b})$ and presented in Table 3. The kinetic model provides maximum correlation coefficient value $\left(R^{2}=0.998\right.$ and 0.995 , for PSO) and below satisfactory correlation coefficient value $\left(R^{2}=0.576\right.$ and 0.830, for PFO) in CNC and MA-CNC sorbents for Cd(II) ion removal, respectively. Therefore, the study indicated that the PSO model better represents the Cd(II) ion adsorption kinetics, suggesting that more of the removal processes are chemisorption.

3.7. Adsorption Mechanism. The probable mechanism of $\mathrm{Cd}(\mathrm{II})$ ion uptake by $\mathrm{CNC}$ is schematically represented in equation (12) and Figure 11. Results from this figure have presented that the hydroxyl, carbonyl, and carboxyl groups are principally accountable for the uptake of $\mathrm{Cd}(\mathrm{II})$ ions:

$$
\mathrm{Cd}^{2+}(\mathrm{aq})+R(\mathrm{OH}, \mathrm{CO}, \mathrm{COOH}) \longrightarrow \mathrm{Cd}(\mathrm{R}(\mathrm{OH}, \mathrm{CO}, \mathrm{COOH}))^{2+} \text {. }
$$

This adsorption mechanism was performed via electrostatic interactions between the Cd(II) ions and the hydroxyl, carbonyl, and carboxyl groups, and the chemical activity of these functional groups on the surface of CNCs contributes to the uptake process.

3.8. Recycling Test. As a result of cost-effectiveness, the recycling of a provided adsorbent is considered the best skill for the applications of industrial and commercial cases. For this purpose, a series of recycling experiments were conducted after the removal processes to convince the regenerated adsorbent for numerous use. Thus, due to the high adsorption capability of the sorbent materials, the MA-CNC sorbent was nominated for regeneration study. The desorption and regeneration experiments are done by evaluating the $\% \mathrm{R}$ of $\mathrm{Cd}(\mathrm{II})$ ions after the $1^{\text {st }}, 4^{\text {th }}$, and $13^{\text {th }}$ cycles and presented in Figure 12. Regeneration assessments were performed to validate the reusability of the material for real-

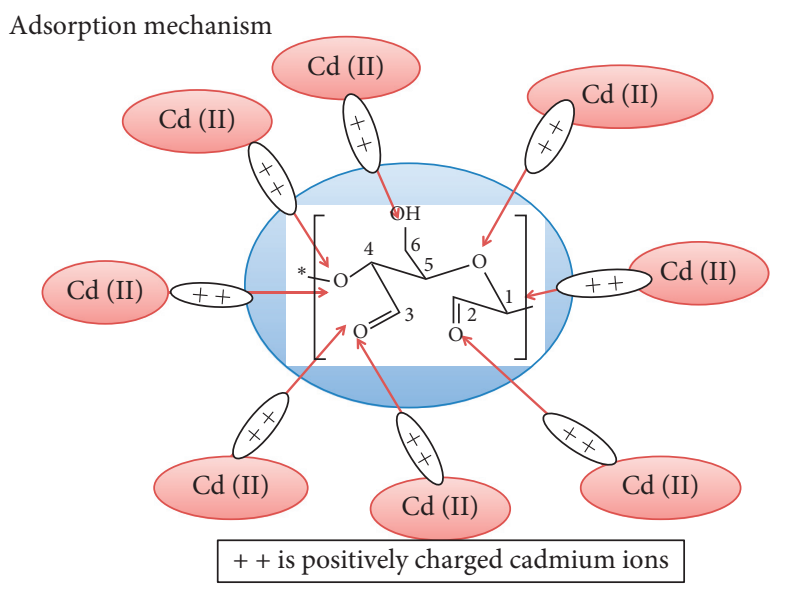

FIgURE 11: Adsorption mechanism of Cd(II) ion removal by CNCs.

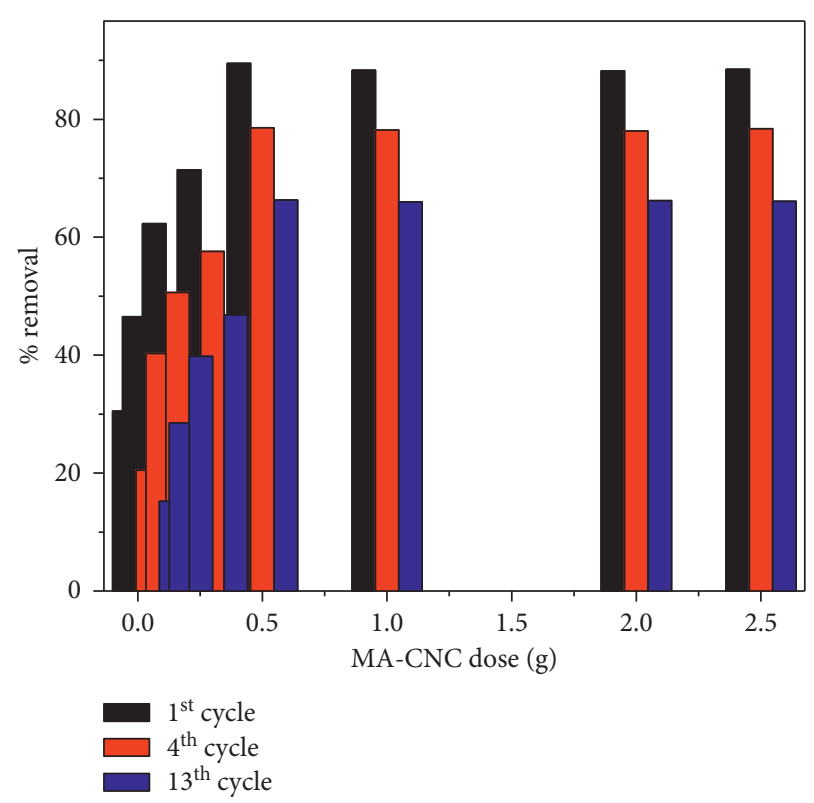

FIGURE 12: Percentage of Cd(II) ions' removal after different cycles $\left(1 \mathrm{st}, 4^{\text {th }}\right.$, and $\left.13^{\text {th }}\right)$ by MA-CNC sorbent.

world applications. Before the regeneration study, the desorption study of the Cd(II) ions for the sorbents with $0.1 \mathrm{M}$ $\mathrm{HCl}$ solution was performed using batch experiments. It is found that the sorption capability of $\mathrm{Cd}(\mathrm{II})$ ions for MA$\mathrm{CNC}$ sorbent gradually reduced with increasing the cycles of reusable tests. The decrease in adsorption ability of the sorbent with increased regularity of reusability times is normal, because of the loss of fresh active surface areas on the MA-CNC sorbent [62]. However, it was found that the 
removal ability of the MA-CNC sorbent did not expressively change after the $13^{\text {th }}$ cycle of experiments as the $\% \mathrm{R}$ was yet pronounced. The decreases in $\% \mathrm{R}$ for the $13^{\text {th }}$ consecutive cycle were no more than $5 \%$. From this, it is possible to deduce that MA-CNC can be used for heavy metal removal for a long time with an outstanding possibility. The results were in agreement with the review study conducted by Liu et al. and Chu et al. $[10,63]$ on the removals of heavy metals from wastewater by using molybdenum disulfide sorbent.

\section{Conclusion}

The present work has shown that both CNC and MA-CNC as a cheap adsorbent have a significant adsorption capability toward Cd(II) ions from WW. The achieved results indicate that \% R by CNC and MA-CNC adsorbent is affected by the adsorption parameters such as solution $\mathrm{pH}$, contact time, agitation speed, initial $\mathrm{Cd}(\mathrm{II})$ ions concentration, and temperature. The maximum adsorption capacities of 75.76 and $215.52 \mathrm{mg} \mathrm{L}^{-1}$ by using both CNC and MA-CNC adsorbents, respectively, were obtained at optimum $\mathrm{pH}$ of 8 , an adsorbent dose of $0.5 \mathrm{~g}$, agitation speed of $250 \mathrm{rpm}$ initial concentration of $20 \mathrm{mg} \mathrm{L}^{-1}$, and contact time of $150 \mathrm{~min}$. In addition to this, the $\% \mathrm{R}$ ability of the MA-CNC sorbents toward $\mathrm{Cd}(\mathrm{II})$ ions in comparison with the $\mathrm{CNC}$ was remarkably enhanced after a maleic reaction with CNC. This is because the proposed mechanisms for the removal process under the optimum condition of MA-CNC sorbent mainly involve the interaction of ester, carboxyl, and hydroxyl groups of cellulose and $\mathrm{Cd}(\mathrm{II})$ ions. The $\mathrm{Cd}(\mathrm{II})$ ion uptake process for both CNC and MA-CNC sorbent systems was fitted with both Langmuir and Freundlich isotherm models. The rate of the interaction between the Cd(II) ions and CNC and MA-CNC sorbents was described by the PSO kinetic model. The recycling experiment results indicated that the used sorbent was recyclable and economically friendly used for the $13^{\text {th }}$ successive cycle as an adsorbent for contaminant removals. Therefore, on the whole, the obtained results suggested that MA-CNC sorbent is considered as an effective adsorbent for the removal of $\mathrm{Cd}(\mathrm{II})$ ions in particular and contaminants in general from the aqueous system.

\section{Data Availability}

The data implemented to support the results of this study are presented within the manuscript.

\section{Conflicts of Interest}

The authors declare that they have no conflicts of interest.

\section{Acknowledgments}

The authors acknowledge Adama Science and Technology University for providing funds and accommodations to do this work. This work was funded by the Project (ASTU, SoANS/JV-259298/2019), Research and Technology Transfer Office, Adama Science and Technology University. In addition to this, the authors thank Dr. Ravikumar C. R.
("DST-SAIF Cochin" center) for his help during sample characterization.

\section{References}

[1] S. Ahuja, J. B. DeAndrade, D. D. Dionysiou, K. D. Hristovski, and B. G. Loganathan, Water Challenges and Solutions on a Global Scale, American Chemical Society, Washington, Dc, USA, 2015.

[2] N. Mohammed, N. Grishkewich, and K. C. Tam, "Cellulose nanomaterials: promising sustainable nanomaterials for application in water/wastewater treatment processes," Environmental Science: Nano, vol. 5, no. 3, pp. 623-658, 2018.

[3] O. A. Oyewo, B. Mutesse, T. Y. Leswifi, and M. S. Onyango, "Highly efficient removal of nickel and cadmium from water using sawdust-derived cellulose nanocrystals," Journal of Environmental Chemical Engineering, vol. 7, no. 4, Article ID 103251, 2019.

[4] S. Egodawatte, A. Datt, E. A. Burns, and S. C. Larsen, "Chemical insight into the adsorption of chromium(III) on iron oxide/mesoporous silica nanocomposites," Langmuir, vol. 31, no. 27, pp. 7553-7562, 2015.

[5] M. Owlad, M. K. Aroua, W. A. W. Daud, and S. Baroutian, "Removal of hexavalent chromium-contaminated water and wastewater: a review," Water, Air, and Soil Pollution, vol. 200, no. 1-4, pp. 59-77, 2009.

[6] J. Shang, M. Zong, Y. Yu, X. Kong, Q. Du, and Q. Liao, "Removal of chromium (VI) from water using nanoscale zerovalent iron particles supported on herb-residue biochar," Journal of Environmental Management, vol. 197, pp. 331-337, 2017.

[7] C. Santhosh, V. Velmurugan, G. Jacob, S. K. Jeong, A. N. Grace, and A. Bhatnagar, "Role of nanomaterials in water treatment applications: a review," Chemical Engineering Journal, vol. 306, pp. 1116-1137, 2016.

[8] P. Phanthong, P. Reubroycharoen, X. Hao, G. Xu, A. Abudula, and G. Guan, "Nanocellulose: extraction and application," Carbon Resources Conversion, vol. 1, no. 1, pp. 32-43, 2018.

[9] T. S. Anirudhan, J. R. Deepa, and J. Christa, "Nanocellulose/ nanobentonite composite anchored with multi-carboxyl functional groups as an adsorbent for the effective removal of Cobalt(II) from nuclear industry wastewater samples," Journal of Colloid and Interface Science, vol. 467, pp. 307-320, 2016.

[10] C. Liu, Q. Wang, F. Jia, and S. Song, "Adsorption of heavy metals on molybdenum disulfide in water: a critical review," Journal of Molecular Liquids, vol. 292, Article ID 111390, 2019.

[11] G. Bhanjana, N. Dilbaghi, K.-H. Kim, and S. Kumar, "Carbon nanotubes as sorbent material for removal of cadmium," Journal of Molecular Liquids, vol. 242, pp. 966-970, 2017.

[12] J. Li, K. Zuo, W. Wu et al., "Shape memory aerogels from nanocellulose and polyethyleneimine as a novel adsorbent for removal of $\mathrm{Cu}(\mathrm{II})$ and $\mathrm{Pb}(\mathrm{II})$," Carbohydrate Polymers, vol. 196, pp. 376-384, 2018.

[13] K. Pyrzynska, "Removal of cadmium from wastewaters with low-cost adsorbents," Journal of Environmental Chemical Engineering, vol. 7, no. 1, Article ID 102795, 2019.

[14] T. S. Anirudhan and F. Shainy, "Effective removal of mercury(II) ions from chlor-alkali industrial wastewater using 2mercaptobenzamide modified itaconic acid-grafted-magnetite nanocellulose composite," Journal of Colloid and Interface Science, vol. 456, pp. 22-31, 2015. 
[15] R. Brandes, D. Belosinschi, F. Brouillette, and B. Chabot, "A new electrospun chitosan/phosphorylated nanocellulose biosorbent for the removal of cadmium ions from aqueous solutions," Journal of Environmental Chemical Engineering, vol. 7, no. 6, Article ID 103477, 2019.

[16] A. Zaman, F. Huang, M. Jiang, W. Wei, and Z. Zhou, "Preparation, properties, and applications of natural cellulosic aerogels: a review," Energy and Built Environment, vol. 1, no. 1, pp. 60-76, 2020.

[17] L. Yu, S. Ruan, X. Xu, R. Zou, and J. Hu, "One-dimensional nanomaterial-assembled macroscopic membranes for water treatment," Nano Today, vol. 17, pp. 79-95, 2017.

[18] Z. Karim, M. Hakalahti, T. Tammelin, and A. P. Mathew, "In situ TEMPO surface functionalization of nanocellulose membranes for enhanced adsorption of metal ions from aqueous medium," RSC Advances, vol. 7, no. 9, pp. 5232-5241, 2017.

[19] E. M. de Melo, J. H. Clark, and A. S. Matharu, "The Hy-MASS concept: hydrothermal microwave assisted selective scissoring of cellulose for in situ production of (meso)porous nanocellulose fibrils and crystalsin situ production of (meso)porous nanocellulose fibrils and crysta," Green Chemistry, vol. 19, no. 14, pp. 3408-3417, 2017.

[20] S. Habibi and M. Jamshidi, "Synthesis of $\mathrm{TiO}_{2}$ nanoparticles coated on cellulose nanofibers with different morphologies: effect of the template and sol-gel parameters," Materials Science in Semiconductor Processing, vol. 109, Article ID 104927, 2020.

[21] F. Rol, M. N. Belgacem, A. Gandini, and J. Bras, "Recent advances in surface-modified cellulose nanofibrils," Progress in Polymer Science, vol. 88, pp. 241-264, 2019.

[22] R. F. S. Barbosa, A. G. Souza, F. F. Ferreira, and D. S. Rosa, "Isolation and acetylation of cellulose nanostructures with a homogeneous system," Carbohydrate Polymers, vol. 218, pp. 208-217, 2019.

[23] M. Salajková, L. A. Berglund, and Q. Zhou, "Hydrophobic cellulose nanocrystals modified with quaternary ammonium salts," Journal of Materials Chemistry, vol. 22, no. 37, pp. 19798-19805, 2012.

[24] X. Liu, H. Ma, and B. S. Hsiao, "Interpenetrating nanofibrous composite membranes for water purification," ACS Applied Nano Materials, vol. 2, no. 6, pp. 3606-3614, 2019.

[25] H. Zhou, H. Zhu, F. Xue, H. He, and S. Wang, "Cellulosebased amphoteric adsorbent for the complete removal of lowlevel heavy metal ions via a specialization and cooperation mechanism," Chemical Engineering Journal, vol. 385, Article ID 123879, 2020.

[26] M. Kumar, A. M. Isloor, T. Somasekhara Rao et al., "Removal of toxic arsenic from aqueous media using polyphenylsulfone/ cellulose acetate hollow fiber membranes containing zirconium oxide," Chemical Engineering Journal, vol. 393, Article ID 124367, 2020.

[27] P. Liu, P. F. Borrell, M. Božič, V. Kokol, K. Oksman, and A. P. Mathew, "Nanocelluloses and their phosphorylated derivatives for selective adsorption of $\mathrm{Ag}^{+}, \mathrm{Cu}^{2+}$ and $\mathrm{Fe}^{3+}$ from industrial effluents," Journal of Hazardous Materials, vol. 294, pp. 177-185, 2015.

[28] Y. Zhou, S. Fu, L. Zhang, H. Zhan, and M. V. Levit, "Use of carboxylated cellulose nanofibrils-filled magnetic chitosan hydrogel beads as adsorbents for $\mathrm{Pb}(\mathrm{II})$," Carbohydrate Polymers, vol. 101, pp. 75-82, 2014.

[29] A. Adel, A. El-Shafei, A. Ibrahim, and M. Al-Shemy, "Extraction of oxidized nanocellulose from date palm (Phoenix Dactylifera L.) sheath fibers: influence of CI and CII polymorphs on the properties of chitosan/bionanocomposite filmsPhoenix Dactylifera L.) sheath fibers: influence of CI and CII polymorphs on the properties of chitosan/bionanocomposite films," Industrial Crops and Products, vol. 124, pp. $155-165,2018$.

[30] J. H. O. D. Nascimento, R. F. Luz, F. M. F. Galvão et al., "Extraction and characterization of cellulosic nanowhisker obtained from discarded cotton fibers," Materials Today: Proceedings, vol. 2, no. 1, pp. 1-7, 2015.

[31] K. Harini, K. Ramya, and M. Sukumar, "Extraction of nano cellulose fibers from the banana peel and bract for production of acetyl and lauroyl cellulose," Carbohydrate Polymers, vol. 201, pp. 329-339, 2018.

[32] X. Yang, F. Han, C. Xu et al., "Effects of preparation methods on the morphology and properties of nanocellulose (NC) extracted from corn husk," Industrial Crops and Products, vol. 109, pp. 241-247, 2017.

[33] H. Tsade, S. T. Anshebo, and F. K. Sabir, "Preparation and characterization of functionalized cellulose nanomaterials (CNMs) for $\mathrm{Pb}(\mathrm{II})$ ions removal from wastewater," Journal of Chemistry, vol. 2021, Article ID 5514853, 18 pages, 2021.

[34] T. Hizkeal, T. A. Sisay, and K. S. Fedlu, "A novel modified cellulose nanomaterials (CNMs) for remediation of chromium (VI) ions from wastewater," Materials Research Express, vol. 7, Article ID 115008, 2020.

[35] H. Afanga, H. Zazou, F. E. Titchou et al., "Integrated electrochemical processes for textile industry wastewater treatment: system performances and sludge settling characteristics," Sustainable Environment Research, vol. 30, no. $1,2020$.

[36] M. Asrofi, H. Abral, A. Kasim, A. Pratoto, M. Mahardika, and F. Hafizulhaq, "Characterization of the sonicated yam bean starch bionanocomposites reinforced by nanocellulose water hyacinth fiber (WHF): the effect of various fiber loading," Journal of Engineering Science and Technology, vol. 13, pp. 2700-2715, 2018.

[37] E. Syafri, Jamaluddin, S. Wahono et al., "Characterization and properties of cellulose microfibers from water hyacinth filled sago starch biocomposites," International Journal of Biological Macromolecules, vol. 137, pp. 119-125, 2019.

[38] G. J. Vadakkekara, S. Thomas, and C. P. R. Nair, "Maleic acid modified cellulose for scavenging lead from water," International Journal of Biological Macromolecules, vol. 129, pp. 293-304, 2019.

[39] L. Zhou, H. He, M.-c. Li, S. Huang, C. Mei, and Q. Wu, "Enhancing mechanical properties of poly(lactic acid) through its in-situ crosslinking with maleic anhydridemodified cellulose nanocrystals from cottonseed hulls," Industrial Crops and Products, vol. 112, pp. 449-459, 2018.

[40] K. C. C. d. C. Benini, H. J. C. Voorwald, M. O. H. Cioffi et al., "Preparation of nanocellulose from Imperata brasiliensis grass using Taguchi method," Carbohydrate Polymers, vol. 192, pp. 337-346, 2018.

[41] R. Lavanya, T. Gomathi, K. Vijayalakshmi, M. Saranya, P. N. Sudha, and S. Anil, "Adsorptive removal of copper (II) and lead (II) using chitosan- g- maleic anhydride- g- methacrylic acid copolymer," International Journal of Biological Macromolecules, vol. 104, pp. 1495-1508, 2017.

[42] L. Segal, J. J. Creely, A. E. Martin, and C. M. Conrad, "An empirical method for estimating the degree of crystallinity of native cellulose using the X-ray diffractometer," Textile Research Journal, vol. 29, no. 10, pp. 786-794, 1959.

[43] D. Wei, Q. Liu, Z. Liu et al., "Modified nano microfibrillated cellulose/carboxymethyl chitosan composite hydrogel with 
giant network structure and quick gelation formability," International Journal of Biological Macromolecules, vol. 135, pp. 561-568, 2019.

[44] H. W. Kwak, H. Lee, S. Park, M. E. Lee, and H.-J. Jin, "Chemical and physical reinforcement of hydrophilic gelatin film with di-aldehyde nanocellulose," International Journal of Biological Macromolecules, vol. 146, pp. 332-342, 2020.

[45] W. Li, B. Ju, and S. Zhang, "Novel amphiphilic cellulose nanocrystals for $\mathrm{pH}$-responsive Pickering emulsions," Carbohydrate Polymers, vol. 229, Article ID 115401, 2020.

[46] M. Thommes, K. Kaneko, A. V. Neimark et al., "Physisorption of gases, with special reference to the evaluation of surface area and pore size distribution (IUPAC technical report)," Pure and Applied Chemistry, vol. 87, no. 9-10, pp. 1051-1069, 2015.

[47] E. R. Cohen, I. Mills, H. L. Strauss et al., "Quantities, units and symbols in physical chemistry," International Union of Pure and Applied Chemistry, vol. 233, pp. 11-13, 2007.

[48] S. A. Younis, H. A. Maitlo, J. Lee, and K.-H. Kim, "Nanotechnology-based sorption and membrane technologies for the treatment of petroleum-based pollutants in natural ecosystems and wastewater streams," Advances in Colloid and Interface Science, vol. 275, Article ID 102071, 2020.

[49] E. Madivoli, P. Kareru, A. Gachanja et al., "Adsorption of selected heavy metals on modified nano cellulose," International Research Journal of Pure and Applied Chemistry, vol. 12, no. 3, pp. 1-9, 2016.

[50] A. Salama, H. A. Aljohani, and K. R. Shoueir, "Oxidized cellulose reinforced silica gel: new hybrid for dye adsorption," Materials Letters, vol. 230, pp. 293-296, 2018.

[51] L. Tang, B. Huang, N. Yang et al., "Organic solvent-free and efficient manufacture of functionalized cellulose nanocrystals via one-pot tandem reactions via one-pot tandem reactions," Green Chemistry, vol. 15, no. 95, pp. 2369-2373, 2013.

[52] Q.-L. Lu, X.-Y. Li, L.-R. Tang, B.-L. Lu, and B. Huang, "Onepot tandem reactions for the preparation of esterified cellulose nanocrystals with 4-dimethylaminopyridine as a catalyst," RSC Advances, vol. 5, no. 69, pp. 56198-56204, 2015.

[53] R. Saravanan and L. Ravikumar, "The use of new chemically modified cellulose for heavy metal ion adsorption and antimicrobial activities," Journal of Water Resource and Protection, vol. 7, no. 6, pp. 530-545, 2015.

[54] F. Almomani, R. Bhosale, M. Khraisheh, A. kumar, and T. Almomani, "Heavy metal ions removal from industrial wastewater using magnetic nanoparticles (MNP)," Applied Surface Science, vol. 506, Article ID 144924, 2020.

[55] E. C. Silva Filho, L. S. Santos Jr., M. M. F. Silva, M. G. Fonseca, S. A. A. Santana, and C. Airoldi, "Surface cellulose modification with 2-aminomethylpyridine for copper, cobalt, nickel and zinc removal from aqueous solution," Materials Research, vol. 16, no. 1, pp. 79-84, 2013.

[56] L. V. A. Gurgel and L. F. Gil, "Adsorption of $\mathrm{Cu}(\mathrm{II}), \mathrm{Cd}(\mathrm{II})$, and $\mathrm{Pb}(\mathrm{II})$ from aqueous single metal solutions by succinylated mercerized cellulose modified with triethylenetetramine," Carbohydrate Polymers, vol. 77, no. 1, pp. 142-149, 2009.

[57] N. Elboughdiri, "The use of natural zeolite to remove heavy metals $\mathrm{Cu}$ (II), $\mathrm{Pb}$ (II) and Cd (II), from industrial wastewater," Cogent Engineering, vol. 7, no. 1, Article ID 1782623, 2020.

[58] Z. Mahmood, S. Zahra, M. Iqbal, M. A. Raza, and S. Nasir, "Comparative study of natural and modified biomass of Sargassum sp. for removal of $\mathrm{Cd}^{2+}$ and $\mathrm{Zn}^{2+}$ from wastewater," Applied Water Science, vol. 7, no. 7, pp. 3469-3481, 2017.

[59] J. N. Putro, A. Kurniawan, S. Ismadji, and Y.-H. Ju, "Nanocellulose based biosorbents for wastewater treatment: study of isotherm, kinetic, thermodynamic and reusability," Environmental Nanotechnology, Monitoring \& Management, vol. 8, pp. 134-149, 2017.

[60] B. Priyadarshini, P. P. Rath, S. S. Behera, S. R. Panda, T. R. Sahoo, and P. K. Parhi, "Kinetics, thermodynamics and isotherm studies on adsorption of eriochrome black-T from aqueous solution using rutile $\mathrm{TiO}_{2}$," IOP Conference Series: Materials Science and Engineering, vol. 310, Article ID 012051, 2018.

[61] H. Tsade, B. Abebe, and H. C. A. Murthy, "Nano sized Fe-Al oxide mixed with natural maize cob sorbent for lead remediation," Materials Research Express, vol. 6, no. 8, Article ID 085043, 2019.

[62] R. Md Lutfor, K. B. Tapan, M. S. Shaheen et al., "Adsorption of rare earth metals from water using a kenaf cellulose basedpoly(hydroxamic acid) ligand," Journal of Molecular Liquids, vol. 243, pp. 616-623, 2017.

[63] Z. Chu, P. Zheng, Y. Yang, C. Wang, and Z. Yang, "Compressible nanowood/polymer composite adsorbents for wastewater purification applications," Composites Science and Technology, vol. 198, Article ID 108320, 2020. 